Published in final edited form as:

J Comp Neurol. 2011 April 1; 519(5): 933-956. doi:10.1002/cne.22559.

\title{
Reassessment of the structural basis of the ascending arousal system
}

\author{
Patrick M. Fuller ${ }^{1}$, David Sherman ${ }^{1}$, Nigel P. Pedersen ${ }^{1}$, Clifford B. Saper ${ }^{1}$, and Jun Lu ${ }^{1}$ \\ ${ }^{1}$ Department of Neurology, Division of Sleep Medicine, and Program in Neuroscience Harvard \\ Medical School and Beth Israel Deaconess Medical Center, Boston, MA 02215
}

\begin{abstract}
The "ascending reticular activating system" theory proposed that neurons in the upper brainstem reticular formation projected to forebrain targets that promoted wakefulness. More recent formulations have emphasized that most neurons at the pontomesencepahlic junction that participate in these pathways are actually in monoaminergic and cholinergic cell groups. However, cell-specific lesions of these cell groups have never been able to reproduce the deep coma seen after acute paramedian midbrain lesions that transect ascending axons at the caudal midbrain level. To determine whether the cortical afferents from the thalamus or the basal forebrain were more important in maintaining arousal, we first place large cell-body specific lesions in these targets. Surprisingly, extensive thalamic lesions had little effect on EEG or behavioral measures of wakefulness or on c-Fos expression by cortical neurons during wakefulness. In contrast, animals with large basal forebrain lesions were behaviorally unresponsive, had a monotonous sub- $1 \mathrm{~Hz}$ EEG, and little cortical c-Fos expression during continuous gentle handling. We then retrogradely labeled inputs to the basal forebrain from the upper brainstem, and found a substantial input from glutamatergic neurons in the parabrachial nucleus and adjacent pre-coeruleus area. Cell specific lesions of the parabrachial-precoeruleus complex produced behavioral unresponsiveness, a monotonous sub- $1 \mathrm{~Hz}$ cortical EEG, and loss of cortical c-Fos expression during gentle handling. These experiments indicate that in rats the reticulo-thalamo-cortical pathway may play a very limited role in behavioral or electrocortical arousal, while the projection from the parabrachial nucleus and precoeruleus region, relayed by the basal forebrain to the cerebral cortex, may be critical for this process.
\end{abstract}

\section{Keywords}

thalamus; sleep; coma; basal forebrain; parabrachial

\section{Introduction}

During cortical arousal the electroencephalogram (EEG) directly reflects the collective synaptic potentials of inputs largely to pyramidal cells within the neocortex and hippocampus (Hasenstaub et al., 2005). The thalamo-cortical system has been widely considered to be a major source of this activity (Steriade et al., 1993; Llinas and Steriade, 2006). The overall level of activity in the thalamo-cortical system, in turn, is thought to be regulated by the ascending arousal system. This system was first proposed in 1949 by Moruzzi and Magoun (1949), who found that destruction of the putative origin of this system in the mesopontine reticular formation by intercollicular transection or electrolytic lesions in cats (Bremer, 1937; Lindsley et al., 1949) caused acute coma. Subsequent studies showed that lesions at the level of the rostral pons, but not in the midpons or more caudally, could cause coma both in animals (Batini, 1959) and in humans (Parvizi and Damasio, 2003; 
Posner et al., 2007). Hence the origin of the ascending arousal system had to begin in the rostral pons.

The course of the ascending arousal pathway was first identified in experiments tracing the degenerating axons in animals after lesions of the midbrain reticular formation that caused coma. These studies showed that the arousal pathway passed through the paramedian midbrain reticular formation, and bifurcated at the diencephalon into two branches that ran, respectively, into the thalamus and hypothalamus (Nauta and Kuypers, 1958). Subsequent studies demonstrated that most of the neurons participating in these pathways from the rostral pons and caudal midbrain belonged to the noradrenergic locus coeruleus (LC), the serotoninergic dorsal (DRN) and median raphe nuclei $(\mathrm{MnRN})$, the cholinergic pedunculopontine (PPT) and laterodorsal tegmental nuclei (LDT), or the parabrachial nucleus (for review, Saper et al., 2005; Fuller et al., 2006). The arousal influence from the mesopontine tegmentum has largely been attributed to the monoaminergic and cholinergic components of this projection (see Saper, 2005 for review). However, cell-body specific lesions using chemical toxins in these latter cell groups have caused relatively limited alterations of wakefulness in rats and cats (Webster and Jones, 1988; Denoyer et al., 1991; Shouse and Siegel, 1992; Datta and Hobson, 1995; Lu et al., 2006b; Blanco-Centurion et al., 2007). Interestingly, despite the inclusion of the parabrachial nucleus in most of the rostral pontine lesions that cause coma in humans (Parvizi and Damasio, 2003), we are not aware of any studies testing whether this cell group plays a role in arousal.

The relative influence of the two branches of the arousal system has also not been resolved. The thalamic branch, which innervates the intralaminar, relay, and reticular nuclei, has been thought to play a critical role in regulating thalamo-cortical transmission and the EEG activity associated with sleep and wakefulness. A second branch runs through the lateral hypothalamus and basal forebrain, where it is augmented by additional neurons that project directly to the cerebral cortex. The activity patterns of these basal forebrain neurons correlate with wake-sleep patterns and EEG waveforms (Lee et al., 2004, 2005) and they are thought to play a more diffuse role in cortical arousal (Saper et al., 2005). Surprisingly, several studies of the role of the thalamus in arousal, employing lesions or local inactivation with lidocaine, consistently have found persistent cortical activation (Dringenberg and Olmstead, 2003; Starzl et al., 1951; Vanderwolf and Stewart, 1988; Villablanca and SalinasZeballos, 1972). On the other hand, lesions that damage the ascending arousal system in the lateral hypothalamus have been known for many years to cause profound sleepiness (Ranson, 1938; Nauta, 1946; Geraschenko et al., 2001), as does injection of a local anesthetic, procaine, into the basal forebrain (Cape and Jones, 2000). Cell specific lesions in the basal forebrain have been found to cause slowing of the cortical EEG (Buzsaki et al., 1988; Kaur et al., 2008), although not the profound coma seen with brainstem lesions.

Given that lesions in the forebrain targets of the ascending arousal system had not been reported to produce the same profound loss of wakefulness as acute damage in the upper brainstem, we decided to re-examine the organization of the arousal system by placing cellspecific lesions in the thalamus and basal forebrain. We also examined the effect of lesions of the parabrachial region in the rostral pons on wakefulness, as this is a key source of inputs to the forebrain components of arousal systems, but its role has not to our knowledge been tested. Finally, we looked at whether the neurons projecting from the parabrachial nucleus to the basal forebrain might be excitatory, using in situ hybridization for the vesicular glutamate 2 transporter. These studies suggest a critical and previously unappreciated role for an ascending glutamatergic arousal pathway from the parabrachial and precoeruleus complex to the basal forebrain in maintaining a wakeful state. 


\section{Materials and Methods}

\section{Animals}

Pathogen free adult male Sprague Dawley rats (275-300 grams, Harlan) were housed in individual cages. The cages were housed inside isolation chambers, which provided ventilation, computer-controlled lighting (12:12 light-dark cycle, lights on at 0700; 200 lux), an ambient temperature of $22 \pm 1^{\circ} \mathrm{C}$, and visual isolation. Care of the rats in the experiment met National Institutes of Health standards, as set forth in the Guide for the Care and Use of Laboratory Animals and all protocols were approved by the BIDMC and Harvard Medical School Institutional Animal Care and Use Committees.

\section{Overall Experimental Design}

In the first part of the present study, we determined the effect of cell-body specific lesions of the thalamus or BF on the cortical EEG, including changes in sleep-wake regulation. Briefly, cell-body specific lesions were placed in the thalamus by injecting $50 \mathrm{nl}$ of a $10 \%$ solution of ibotenic acid bilaterally (see below). Lesions of the basal forebrain were done by injecting a $0.1 \%$ solution of either IgG192-saporin or orexin-saporin at four different sites (see below). EEG/EMG electrodes were implanted at the same surgery, and continuous recordings began on day 7 postoperatively. At the end of the study, animals were behaviorally stimulated (see below) for two hours, then anesthetized and killed by formaldehyde perfusion, and the brains were removed and processed for c-Fos immunohistochemistry. For animals that were spontaneously active, behavioral stimulation consisted of placing two cages together and removing the tops. Animals would jump back and forth between the cages, and maintained spontaneous wakefulness, even during the light period, for two hours from 10:00 to 12:00. In cases where animals were not spontaneously active, they were stimulated by the experimenter by gentle handling and stroking with a paintbrush for the two hour period.

In the second part of the study, we used cholera toxin subunit B (CTB) to retrogradely trace inputs to the BF and thalamus from sites in the brainstem to define the cell groups whose activity is important for maintaining a normal waking state. We combined this with in situ hybridization for the vesicular glutamate 2 transporter (VGLUT2), to determine which of these cells were likely to be glutamatergic.

In the third part of the study, we used local injections of orexin-saporin to ablate neurons in the parabrachial nucleus and precoeruleus region, which had been found to represent a major brainstem source of glutamatergic inputs to the basal forebrain. Again, animals were implanted with EEG/EMG electrodes, and continuous recordings began seven days postoperatively. At the end of the experiment, we also examined c-Fos immunoreactivity in the brains of these animals after two hours of behavioral stimulation, as in the first part of the study.

\section{EEG/EMG and sleep recording}

The surgery, EEG/EMG data collection and analyses have been described in detail previously (Lu et al., 2006a and Lu et al., 2006b). In brief, after animals were anesthetized with chloral hydrate ( $7 \%$ in saline, $350 \mathrm{mg} / \mathrm{kg}$ ), the skulls were exposed. Four EEG screw electrodes were implanted into the skull, in the frontal (two) and parietal bones (two) of each side, and two flexible EMG wire electrodes were placed into the neck muscles. The free ends of the leads were soldered into a socket that was attached to the skull with dental cement, and the incision was then closed by wound clips. On post-surgical day 3 , the sockets were connected via flexible recording cables and a commutator to a Grass polygraph and computer. From day 7 until the completion of each experiment, signals were recorded 
continuously. Signals were digitized using an Apple Macintosh computer running the ICELUS sleep recording system (M. Opp, University of Michigan, Ann Arbor, MI). EEG signals were filtered to exclude frequencies $<0.5$ or $>35 \mathrm{~Hz}$, whereas EMG signals were filtered to exclude frequencies $<10$ or $>35 \mathrm{~Hz}$. Briefly, NREM sleep was identified by a preponderance of high-amplitude, low-frequency $(<4 \mathrm{~Hz})$ EEG activity and relatively low and unchanging EMG activity, whereas wakefulness was characterized by a preponderance of low-amplitude, fast EEG activity and highly variable muscle tone on EMG. REM sleep was identified by very low EMG activity and a low-amplitude monotonous EEG containing a predominance of theta range $(4-7 \mathrm{~Hz})$ EEG activity. Scoring was done before histological examination and so the scorers were unaware of the extent of the lesions.

Wake-sleep states were manually scored in $12 \mathrm{~s}$ epochs on the digitized EEG/EMG. The amount of time spent in wake, NREM sleep, and REM sleep was determined for each hour. Twenty-four hour fast Fourier transform (FFT) power spectrum plots for all animal groups were also generated. Additional FFT analysis was performed on several short representative EEG epochs (ca. $12 \mathrm{sec}$ ).

\section{Tracer and neurotoxin injections}

Under chloral hydrate anesthesia ( $7 \%$ in saline, $350 \mathrm{mg} / \mathrm{kg}$ ), a burr hole was made and a fine glass pipette ( $1 \mathrm{~mm}$ glass stock, tapering slowly to a $10-20 \mu \mathrm{m}$ tip) containing $1.0 \%$ CTB (List Biological), $10 \%$ ibotenic acid, or $0.1 \%$ orexin saporin (OX-SAP) or IgG192-saporin (192-SAP) (Advanced Targeting Systems) was lowered to the pre-determined targets (Paxinos and Watson, 1986). Coordinates for the BF include: magnoceullar preoptic nucleus (MCPO): $\mathrm{AP}=-0.36 \mathrm{~mm}, \mathrm{DV}=7.5 \mathrm{~mm}, \mathrm{ML}= \pm 3.0 \mathrm{~mm}$; substantia innominata (SI; corticopetal neurons within the SI are also called the nucleus basalis): $\mathrm{AP}=-1.08 \mathrm{~mm}$, DV $=7.4 \mathrm{~mm}, \mathrm{ML}= \pm 3.0 \mathrm{~mm}$; medial septal-diagonal band complex $(\mathrm{MS}): \mathrm{AP}=0.84 \mathrm{~mm}, \mathrm{DV}=$ $6.6 \mathrm{~mm}, \mathrm{ML}=0 \mathrm{~mm}$. Coordinates for the thalamus: $\mathrm{AP}=3.15 \mathrm{~mm}, \mathrm{DV}=5.4 \mathrm{~mm}, \mathrm{ML}= \pm$ $1.5 \mathrm{~mm}$. Injections were made slowly (over five minutes) by gentle puffs of air pressure, and the pipette was left in place for five minutes after the injection was completed. Incisions were closed with wound clips and animals were allowed to recover for 7 days.

In the present study, cell-body specific neural lesions were generated using either an excitotoxin (ibotenic acid) or saporin-based immunotoxins (orexin-saporin or IgG192saporin). While ibotenic is an excellent toxin for areas of the brain that receive a lot of glutamatergic inputs, such as the thalamus, it has two important drawbacks in other areas of the brain, such as the basal forebrain, hypothalamus and brainstem. First, ibotenic acid does not necessarily kill all cell groups (e.g., the tuberomammillary nucleus is resistant to it), and second it may cause excitatory autonomic responses that can compromise circulation or breathing. Orexin-saporin on the other hand has the advantage of causing a slower, nonexcitotoxic cell death, allowing animals to survive lesions that might otherwise have lethal side effects if done by ibotenic acid. In addition, neurons are differentially susceptible to orexin-saporin (for example, suprachiasmatic neurons are highly resistant to it; Lu and Saper, unpublished observations). In our experiments, orexin-saporin differentially killed non-cholinergic basal forebrain cells at lower concentrations, but killed all basal forebrain cells at higher concentrations; see Results. By contrast, IgG192-saporin kills only cholinergic cells in the basal forebrain (Smith and Pang, 2005).

\section{Histology}

Animals were killed by deep anesthesia with $500 \mathrm{mg} / \mathrm{kg}$ of chloral hydrate, followed by perfusion through the heart with $50 \mathrm{ml}$ saline, followed by $250 \mathrm{ml}$ of neutral phosphate buffered formalin (Fischer Scientific Co.). Brains were removed, incubated in $20 \%$ sucrose at $4^{\circ} \mathrm{C}$ until they sank, and then sectioned at $40 \mu \mathrm{m}$ on a freezing microtome in four series. 
Sections were washed in phosphate buffered saline (PBS, $\mathrm{pH}$ 7.4), and incubated in primary antiserum (antibody characterization below) diluted in PBS containing 0.3\% Triton X-100 and $0.2 \%$ sodium azide for one day at room temperature. Sections were then washed in PBS and incubated in biotinylated secondary antiserum (against appropriate species IgG, 1:1000, Vector) in PBS for one hour, washed in PBS and incubated in ABC reagents for 1 hour.

Sections were then washed again and incubated in a solution of 0.06\% 3,3-diaminobenzidine tetrahydrochloride (DAB, Sigma) and $0.02 \% \mathrm{H}_{2} \mathrm{O}_{2}$. The sections were stained brown with DAB (ChAT) or black (c-Fos) by DAB plus $0.05 \%$ cobalt chloride and $0.01 \%$ nickel ammonium sulfate.

\section{Antibody characterization}

Table 1 provides a list of all antibodies used in the present study. The rabbit polyclonal Fos antibody was raised against a synthetic peptide including residues 4-17 from human c-Fos. This antibody stained a single band of $55 \mathrm{kD} \mathrm{m}$.w. on Western blots from rat brain (manufacturer's technical information). c-Fos staining with the Ab5 antiserum is found in many CNS structures (Gooley et al., 2006; Lu et al., 2006) only when neurons within these structures have recently been physiologically stimulated.

The rabbit polyclonal antibody against orexin A was raised against the orexin peptide PyrPro-Leu-Pro-Asp-Cys-Cys-Arg-Gln-Lys-Thr-Cys-Ser-Cys-Arg-Leu-Tyr-Glu-Leu-Leu-HisGly-Ala-Gly-Asn-His-Ala-Ala-Gly-Ile-Leu-Thr-Leu-NH2. On immunoblots from rat brain, it recognizes a pair of bands representing the orexin peptides at about $3.5 \mathrm{kD} \mathrm{m} . \mathrm{w}$. (manufacturer's technical information). The pattern of cellular morphology and distribution that is stained is limited to the lateral hypothalamus and is identical to previous reports (Chou et al., 2003). Adsorption controls have been reported previously to result in elimination of staining by the antibodies that we used against orexin-A (Chen et al., 1999).

The goat polyclonal antibody against ChAT was raised against human placental enzyme, and only a single band of appropriate molecular weight was identified by immunoblot in mouse NIH/3T3 cell lysates (manufacturer's technical information). In the basal forebrain and the mesopontine tegmentum, it stains a pattern of cellular morphology and distribution identical to previous reports (Chou et al., 2002).

The mouse monoclonal antibody against Tyrosine Hydroxylase (TH) was raised against TH isolated and purified from rat PC12 cells. Adsorption controls have been reported previously to result in elimination of staining by the antibodies that we used against TH (GonzalesCuello et al., 2004).

The goat polyclonal antibody against Cholera toxin subunit B was raised against CTB and the specificity of immunostaining for CTB was indicated by the lack of detectable immunostaining in uninjected rats.

For all secondary antibody immunohistochemical controls, the primary antibodies were omitted and the tissue showed no immunoreactivity above background.

\section{Double-staining of VGLUT2 mRNA by in situ hybridization and cholera toxin subunit B (CTB) by immunohistochemistry}

We used a method we have previously described (Chou et al., 2002; Lu et al., 2006; Lu et al., 2002) to label CTB with an immunoperoxidase brown color and then VGLUT2 mRNA by autoradiography. Briefly, sections ( $40 \mu \mathrm{m}$ thickness) were first stained immunohistochemically for CTB (brown DAB reaction), as above, except that all solutions were DEPC treated to destroy RNAase. The sections were then acetylated and hybridized overnight $\left(55^{\circ} \mathrm{C}\right)$ with a ${ }^{35} \mathrm{~S}$-labeled cRNA probe synthesized from a plasmid containing the 
complete coding sequence of VGLUT2 mRNA. After a succession of one hour washes $\left(2 \mathrm{xSSC} / 1 \mathrm{mM}\right.$ DTT, $50{ }^{\circ} \mathrm{C} ; 0.2 \mathrm{xSSC} / 1 \mathrm{mMDTT}, 55^{\circ} \mathrm{C} ; 0.2 \mathrm{xSSC} / 1 \mathrm{mM}$ DTT, $\left.60{ }^{\circ} \mathrm{C}\right)$, the tissue was treated with RNAase-A (Boehringer-Mannheim, Indianapolis) and washed under conditions of increasing stringency, including a $30 \mathrm{~min}$ wash at $60^{\circ} \mathrm{C}$ in $0.1 \times \mathrm{SSC}$. The tissue was then dehydrated in alcohol and air-dried. The sections were exposed to X-ray film (Eastman-Kodak) for 2-3 days; the slides were then dipped in Kodak NTB-2 emulsion and exposed for one month. Slides were developed in Kodak D-19, fixed, and then dehydrated and cover-slipped.

\section{Cell profile counting}

Cell profile counts were used both to assess completeness of lesions (counts of all remaining neurons in a field in three sections per region), and to measure the number of Fosimmunoreactive neurons in selected brain regions after behavioral stimulation. In all cases, cell profiles were counted only when there was a clearly distinguishable nucleus. In the case of lesions, the nucleus appeared as a clear area in either a Nissl or immunostained neuron. In the Fos studies, the nucleus was stained black. Lesions of BF cholinergic neurons were determined by counting remaining ChAT-ir cells in all the BF containing sections, and comparing results to controls. As the same tissues were Nissl counterstained, we were able to count remaining non-cholinergic cells as well. For counting non-cholinergic neurons, the ChAT-ir field (in corresponding sections from unlesioned brains) was used to mark the counting region. The orexin field in the lateral hypothalamus was similarly localized from immunostained sections. The $\mathrm{PC}$ and the $\mathrm{PB}$, as well as the ventrolateral tuberomammillary nucleus (TMN) and locus coeruleus (LC) counting fields were defined by their location in Nissl counterstained sections. Profiles containing Fos-ir nuclei were counted in two consecutive (1:4) sections through the center of the cell group for the PC and four sections for the PB, TMN, lateral hypothalamic orexin neurons (OX) and LC on both sides of the brain. As the level of c-Fos expression was similar across the cerebral cortex and in the same laminar pattern as in non-lesioned rats during normal wakefulness, we chose to quantify Fos expression in the cingulate cortex (CC) in the control animals and those with thalamic lesions (Figure 1). For the $\mathrm{CC}$, a $0.3 \times 0.3 \mathrm{~mm}$ counting box was placed on one side of the brain with one border parallel to and along the edge of layer 1 at the level of the genu of the corpus callosum, which included the full thickness of layers I-VI, where the Fosimmunoreactive neurons were found. The profile counts were then corrected by the Abercrombie equation, where the corrected count $N=n \times T /(D+T)$ where $n$ is the uncorrected count, $\mathrm{T}$ is thickness of the tissue section, and $\mathrm{D}$ is mean nuclear diameter. Brightness and contrast of images were optimized for visualization purposes, and figures were created in Adobe Photoshop and Illustrator.

\section{Statistical Analysis}

We analyzed the percent time spent in wake and sleep states and the Fos expression in the brain by using an ANOVA. Post-hoc testing (Tukey's HSD) was used for individual mean comparisons where appropriate. Because all data conformed to the requirements of the ANOVA model, we did not need to take any remedial measures for transforming the response variables. An $\alpha<0.05$ was considered significant.

\section{Results}

\section{Role of thalamus and basal forebrain in cortical EEG}

Effect of ibotenic acid lesions of the thalamus on sleep-wake behavior and EEG-We first examined the role of the thalamus in maintaining wakefulness in a series of rats that received bilateral injections of 60-66 nl per side of ibotenic acid $(\mathrm{n}=10)$ or saline as a control $(n=6)$ into the thalamus and were implanted to record EEG and EMG chronically. 
Recordings began one week after surgery and were continuously recorded for at least five days for each animal.

Lesion areas were mapped in Nissl stained sections. In four rats with nearly complete thalamic lesions, the medial (parataenial and mediodorsal), anterior (anterodorsal, anteroventral, anteromedial, and laterodorsal), ventral (ventroanterior, ventrolateral, ventroposterior, and posterior), and intralaminar and midline (reuniens, paraventricular, rhomboid, centromedial, centrolateral, paracentral, and parafascicular) nuclei were all nearly completely eliminated. Only a small portion of the reticular nucleus around the rim of the thalamus and the far caudal parts of the posterior and the medial and lateral geniculate nuclei were spared (Figures 1a, 2). Given that we recorded EEG mainly from the fronto-parietal regions of the cortex that are served by the anterior, medial, and ventral groups, these animals with large thalamic lesions provide an estimate of the degree of cortical arousability and EEG activity in areas that had been subjected to thalamic deafferentation.

Compared to the controls, rats even with very extensive thalamic lesions (Figure 2 and $3 b$ ) showed remarkably normal EEG/EMG patterns, with no significant changes in amounts of NREM sleep and REM sleep, or in the circadian pattern of sleep (Table 2). We also examined the structure of the EEG rhythms in the rats with thalamic lesions. The EEG power spectrum during wakefulness, NREM sleep, and REM sleep in rats with thalamic lesions was indistinguishable from controls, with the exception of a decrease in theta power during the subjective night (Figure 4a and $b$ ) and the loss of EEG sleep spindles in animals with thalamic lesions. In control animals, spindles were mostly seen during NREM-REM transition, over a period of about one minute during state transition in which an average of 3-4 sleep spindles were observed. In rats with large thalamic lesions, spindles were no longer observed during the NREM-REM transitions or at other times.

Behaviorally, the rats with thalamic lesions responded to sensory stimuli such as pinching, touching, and sound, as had been reported in earlier studies (Vanderwolf and Stewart, 1988; Villablanca and Salinas-Zeballos, 1972). They also could find food in their cages, and could jump from cage to cage, suggesting retained cortical vision, which would be consistent with the preservation of the lateral geniculate nucleus. We did not test animals for complex behaviors such as pattern recognition and as such we cannot draw conclusions about the behavioral normalcy in these animals. However, in the environment in which we tested them, it would have been difficult for a blinded observer to distinguish the rats with thalamic lesions from controls.

To examine cortical activity during aroused behavior, rats with large thalamic lesions and control rats were individually placed in open-lid cages with access to neighboring cages. For the next two hours, the rats were allowed to move freely between adjacent cages. Under these conditions, both control rats and those with large thalamic lesions were highly active and aroused (i.e., had minimal behavioral or EEG evidence of sleep), without any human intervention. Rats were then perfused and brains were processed for Nissl staining and Fos immunohistochemistry. While Fos expression is not a direct measure of neuronal firing, it gives a rough indication of the degree to which neurons have been receiving excitatory inputs that elevate cyclic AMP or intracellular calcium. Rats with large thalamic lesions had Fos expression diffusely throughout the cerebral cortex (including areas of the frontal and parietal cortex subserved by the ablated thalamic areas, fig. $1 \mathrm{~b}$ and the cingulate cortex, for which numbers of Fos-immunoreactive neurons were quantified in Table 3) that was indistinguishable from awake control animals. The rats with large thalamic lesions also showed normal aroused waking levels of Fos expression in the components of the ascending arousal system, including the histaminergic tuberomammillary nucleus (TMN), lateral hypothalamic orexin (OX) neurons, and the noradrenergic LC (Figure 1b-g, Table 3), three 
cell groups associated with arousal which typically express Fos when animals are behaviorally stimulated as in this study.

Effect of lesions of the BF magnoceullar system on cortical arousal-The BF includes magnocellular corticopetal cholinergic and non-cholinergic (largely GABAergic) neurons in the medial septal-diagonal band complex, the medial part of the globus pallidus, the magnoceullar preoptic nucleus (MCPO), and the substantia innominata (SI) (Zaborszky et al, 2005; Saper, 1984). In the first experiment, we made large, non-selective lesions to attempt to destroy the entire BF corticopetal projection system.

To do this, we used high dose injections of OX-SAP ( $25 \mathrm{ng} /$ site at five sites: one in the medial septum in the midline, one on each side in the MCPO and in the SI) in eleven rats. OX-SAP takes 7-10 days to kill neurons. OX-SAP was used to kill BF neurons rather than ibotenic acid, because we found in preliminary experiments that injections of ibotenic acid in doses large enough to kill most BF neurons resulted in an unacceptably high rate of operative death, presumably from diffusion of the excitatory amino acid into autonomic regulatory sites in the nearby preoptic area. Although it has been proposed that OX-SAP may selectively kill neurons with orexin receptors (Gerashchenko et al, 2001), we found that it killed virtually all basal forebrain neurons, although the cholinergic neurons were somewhat resistant at lower doses (see below). We found no evidence of retrograde injury to cell groups that project to the BF (e.g., the lateral hypothalamic orexin neurons, tuberomammillary neurons, or locus coeruleus, see fig. 1). Recordings were done continuously from day 7 post-operatively for at least seven days, until the end of the experiment. At around the tenth day post-surgery, the seven rats with large, bilateral BF lesions started (typically quite abruptly) to exhibit a coma-like state (Figure 5 and 6). The four animals with partial lesions (illustrated by asterisks in Fig. 6) remained spontaneously active, while the seven comatose-like rats did not respond to sounds or pinching, although they did retain brainstem reflexes such as the righting reflex, loss of which is traditionally considered a sign that an animal is asleep or anesthetized. The rats also did not voluntarily eat food or drink water, even if food or water was placed in their mouths. We kept the animals alive for 5-7 days following the onset of the 'coma-like' behavioral state by injecting daily $10 \mathrm{mls}$ intraperitoneally of a solution containing $0.9 \%$ saline and $5 \%$ sucrose. This coma-like behavioral state was marked by a monotonous high voltage slow wave EEG pattern although the EMG tone varied considerably across the day. For example, during the presumptive active period, animals would occasionally stand and even walk a step or two, but still with a monotonous slow wave EEG pattern, which we interpreted as representing putative hypothalamic and brainstem wake activity without cortical waking (akin to sleepwalking; Figure 5). However, no purposeful behavior (e.g., approaching food or water sources) was ever observed. We did not attempt to keep animals alive beyond 7 days in this state, so do not know whether they might eventually have recovered waking states. Power spectrum analysis showed that the EEG at all times sampled was dominated by sub-delta $(<1.0 \mathrm{~Hz}$ EEG) activity in these animals (Figure $4 \mathrm{a}$ and b). Post-mortem brain analysis revealed that virtually all non-cholinergic neurons and $\sim 88 \%$ of cholinergic neurons $(18.0 \pm$ 7.2 surviving ChAT-positive neurons/section/side) in the MBN were eliminated. Most of the surviving ChAT-positive neurons were located at the margins of the lesion field (see Figure $5 a, b)$ where they were the only surviving nerve cells, suggesting that they might be more resistant to the OX-SAP toxin than the other surrounding cell types.

To determine the effect of behavioral activation on Fos expression in the arousal system in rats with non-selective BF lesions (Figure 6), we monitored the EEG/EMG during behavioral stimulation for two hours (10:00-12:00) and then immediately perfused the animals. Control rats showed continual wakefulness throughout this period when placed in cages without lids, but to maintain a tonically active EMG in the 'coma-like' rats we had to 
stimulate the animals by continuous gentle touching. Despite this constant additional stimulation, the EEG continued to show monotonous slow-wave activity and the neocortex of the coma-like animals showed minimal Fos expression (Figure 5c, Table 3), similar to the states of deep sleep or deep general anesthesia (Lu et al., 2008). However, the coma-like animals exhibited a high level of Fos expression in the brainstem, thalamic, and hypothalamic components of the ascending arousal systems (i.e., the TMN, OX neurons, and the LC, see Table 3 and Figures 5d,e, and 7) that was similar to the control waking animals. These findings demonstrate that even when the brainstem, thalamus, and hypothalamus of rats are brought to a state of high arousal, neurons in the $\mathrm{BF}$ are critical for activating the cerebral cortex to produce EEG and behavioral arousal.

Because these effects were far more profound than previous reports from more limited BF lesions, we next examined the effects of extensive but chemically selective BF lesions on behavior, sleep-wake, and Fos expression in the brains of rats. For lesions of the cholinergic neurons, five rats received IgG 192-saporin $(1.0 \mu \mathrm{g})$ injections into the lateral ventricle. Consistent with several prior studies(Berntson et al., 2002; Blanco-Centurion et al., 2006; Kaur et al., 2008; Kapas et al., 1996; Wenk et al., 1994) loss of BF cholinergic neurons (up to $95 \%$ ) did not have lasting effects on the percent of time spent in wakefulness, NREM, or REM sleep, or Fos expression in the neocortex, TMN, OX neurons, or LC during aroused wakefulness (Table 2-3 and Figure 8a-d). We examined the EEG power spectrum during wake, NREM, and REM sleep, and found no differences as compared with unlesioned control rats (Figure 3a and c).

Next we examined the effects of selective lesions of the non-cholinergic BF neurons. We were able to do this because of the fortuitous observation in our preliminary studies in which we used different doses of OX-SAP, that injections of $100 \mathrm{ng}$ OX-SAP $(20 \mathrm{ng} / \mathrm{site}, \mathrm{n}=5)$, although only $20 \%$ smaller than the dose that caused non-selective destruction, killed virtually all non-cholinergic neurons in the BF, but only about $19 \%$ of cholinergic neurons in the MBN (103.2 \pm 8.1 cholinergic neurons /section/side remained) (Figure 8). Similar to rats with selective lesions of cholinergic BF neurons, the rats with selective lesions of noncholinergic neurons showed no alterations in sleep-wake behaviors or Fos expression during arousal (Figure 8e-j, Table 3). The EEG power spectrum during wake, NREM, and REM sleep was indistinguishable from unlesioned control rats (Figure $3 \mathrm{a}$ and $\mathrm{d}$ ). These results suggest that both the cholinergic and non-cholinergic (predominantly GABAergic) BF neurons work jointly in control of cortical arousal, and that either component alone is capable of supporting cortical arousal. However, the profound loss of behavioral responsiveness in rats with lesions of the entire MBN neuronal population suggests that the $\mathrm{BF}$ is a critical relay for maintaining the waking pattern of behavior, EEG, and cortical cFos expression in rats. We therefore next searched for inputs to the BF neurons from the critical level of the rostral pons that is necessary to maintain a waking state.

\section{The parabrachial nucleus (PB) and precoeruleus_area (PC) provide critical neuronal inputs for maintaining cortical arousal}

The PB and PC project to the BF-To identify the possible brainstem sources providing arousal inputs to the $\mathrm{BF}$ that might mediate its activation during arousal, the retrograde tracer cholera toxin subunit $\mathrm{B}(\mathrm{CTB}, 1.0 \%, 15 \mathrm{nl})$ was injected into the substantia innominata SI $(\mathrm{n}=4)$ (Ericson and Blomqvist, 1988). Consistent with findings from previous tracing studies (Jones and Yang, 1985; Grove, 1988; Jones and Cuello, 1989) CTB-ir cells were seen in the ventral tegmental area, LC, and DRN. Smaller numbers of retrogradely labeled neurons were found in the LDT and PPT, and moderate numbers of retrogradely labeled cells were found in the ventral periaqueductal gray matter. Although the reticular formation is widely believed to play a major role in regulating wake-sleep states, we found 
only scattered cells in this structure (which may have belonged to the raphe, cholinergic, or noradrenergic systems), averaging only about 3 CTB-ir cells per section. However, in previous studies cell-specific lesions in each of these sites in rats had been found to produce no overall change in the amount of sleep, and typical waking EEG patterns were preserved (Lu et al., 2006a,b).

The CTB injections into the SI (Figure 9) also retrogradely labeled large numbers of neurons in the medial PB (MPB, $22.0 \pm 2.5$ cells/section/injection side) and in the waist region and the ventral subnucleus of the lateral PB (LPB, $8.5 \pm 1.8$ cells/section/injection side) (see also, Moga et al., 1990). In addition, smaller numbers of labeled cells were seen in the PC $(6.5 \pm 0.5$ cells/section/injection side). The PC was previously defined as the region in the lateral corner of the periventricular gray matter of the fourth ventricle, just rostral to the locus coeruleus and just medial to the PB and mesencephalic trigeminal nucleus (see $\mathrm{Xu}$ et al., 2004; Lu et al., 2006b). We had previously shown that the PC provides a major input to the medial part of the BF, including the medial septum and diagonal band nuclei (Lu et al., 2006b).

Because many neurons in the PB/PC are glutamatergic (Lu et al., 2006b; Yokota al., 2007), we performed double-labeling for CTB by immunohistochemistry and for vesicular glutamate transporter 2 (VLGUT2) mRNA, a key marker for glutamatergic neurons in the $\mathrm{PB}$, by in situ hybridization. We found that almost all the CTB-labeled cells in the PC and the PB also expressed VGLUT2 mRNA (Figure 9a-c), indicating that the PB and the PC provide extensive glutamatergic inputs to the BF. As we have reported elsewhere (Lu et al., 2006b), nearly all neurons in the PC that were retrogradely labeled from the MS also contained VGLUT2 mRNA(Lu et al., 2006b). Hence, there is a large and topographically organized projection to the $\mathrm{BF}$ from a population of glutamatergic neurons in the dorsolateral pons that spans from the PC through the MPB and LPB, and in which the most medial pontine sites project to the most medial parts of the MBN, and the most lateral sites to the more lateral MBN.

Lesions of the PB/PC cause hypersomnolence or coma-To determine the potential role of the PC and PB in arousal, OX-SAP lesions $(0.25 \mathrm{mg} / \mathrm{ml})$ were made targeting the PC $(n=4)$, MPB $(n=7)$, LPB $(n=5)$ or the entire PB-PC complex $(n=11$, including partial lesions) (Figure 10). We again used OX-SAP to kill neurons in this region, because injections of large enough amounts of ibotenic acid to cause the lesions resulted in unacceptably high rate of intraoperative death, presumably due to spread of the excitatory amino acid into the autonomic and respiratory control areas of the parabrachial complex. Additional anatomic control lesions, including those that arose naturally from missed injections, were made in contiguous regions of the pontine tegmentum $(n=8$; see Figure 11 and also Lu et al., 2006b), including the sublaterodorsal nucleus, which is located just ventromedial to the PB/PC. Recordings were done continuously from day 7 post-operatively for at least seven days, until the end of the experiment.

LPB lesions alone caused about a $13 \%$ increase in total sleep over the control animals, which was due to a roughly $50 \%$ increase in NREM and a doubling of REM during the dark cycle (when animals are usually awake), both significant at the $\mathrm{p}<0.05$ level (Table 2).

Analysis of the power spectrum during wake, NREM, and REM sleep after LPB lesions did not show any differences as compared with unlesioned control rats (Figure 3a and e).

MPB lesions increased total sleep by about $28 \%$, which was due to an approximate doubling of NREM and tripling of REM sleep during the dark cycle, both significant at $\mathrm{p}<0.01$ (see Table 2). The power spectrum of the EEG recorded during wake, NREM, and REM sleep 
after MPB lesions again showed essentially no change as compared with unlesioned control rats (Figure 3a and f).

We previously showed that discrete PC lesions selectively abolished hippocampal theta EEG during REM sleep, but did not affect total sleep time, NREM time, or REM time (as demonstrated by EMG atonia) (Lu et al., 2006). In addition, bilateral control lesions of adjacent regions of the pontine tegmentum, including the locus coeruleus and paramedian reticular formation produced little change in the proportions of wakefulness vs. NREM or REM sleep (Figure 11, Table 4; also Lu et al., 2006).

In contrast, animals with lesions of the entire $\mathrm{PB} / \mathrm{PC}$ complex became comatose about 10 days after injection of OX-SAP (Figure 10 and Figure 11). We closely monitored the EEG in several PB-PC lesioned rats during the transition to coma and observed an abrupt switch into the comatose state. The comatose rats were kept alive for 5-7 days by injections of a $5 \%$ glucose $-0.9 \%$ saline solution, as after the BF lesions. As with the BF lesions, we euthanized all animals at the end of this time, so do not know whether they might have recovered wakefulness, as has been reported in animals with prolonged recovery periods after midbrain reticular formation lesions (Adametz, 1959). However, animals with complete PB-PC lesions showed a continuous prominent slow wave EEG pattern similar to the coma-like state following BF lesions. Analysis of the $24 \mathrm{~h}$ power spectrum showed that the bulk of the EEG power was in the $<1 \mathrm{~Hz}$ range (Figure $4 \mathrm{a}$ and $\mathrm{b}$ ). During coma, only a few brief motor twitches were observed (i.e., there were no EMG periods of spontaneous activity, as we observed in the animals who were behaviorally unresponsive after large BF lesions), although the righting reflex was intact. In the case of the comatose rats, we also evaluated the integrity of the LDT, PPT and LC cell groups in ChAT stained sections (for PPT and LDT) and Nissl-stained sections (to evaluate the body of the LC). We found modest but variable damage to the PPT and LC in the comatose rats (in no case was there more than $50 \%$ bilateral cell loss in either cell group) and minimal damage to the LDT (never more than 5-10\% cell loss). Figure 12 shows representative sections of these structures at the level of the LDT, PPT (ChAT stained neurons) and LC (Nissl stain) from animals in a coma-like state after $\mathrm{PB} / \mathrm{PC}$ lesions.

After two hours of gentle handling, the comatose rats were perfused and the brains were immunostained for Fos. Compared to the control awake animals, the comatose rats exhibited a very low level of Fos expression in the neocortex (Figure 10, Table 3), comparable to BF lesioned rats. However, unlike the BF lesioned rats, the TMN and OX cell groups showed approximately an $80 \%$ reduction in Fos-ir neurons compared to controls (Table 3). In the thalamus, Fos expression was similar to the sleeping controls (Figure 7). The LC and PPT demonstrated high levels of Fos expression comparable to the aroused controls, indicating brainstem activation by gentle handling (Figure 10, Table 3).

Combined with our previous study on the PC-medial septal (MS) system (Lu et al., 2006), our results suggest that the PC-MS-hippocampal axis regulates hippocampal activation and the PB/PC-BF-neocortical axis controls neocortical arousal. Together these two projections appear to be parallel pathways that constitute a critical ascending arousal influence from the mesopontine tegmentum that is necessary to achieve and maintain an activated EEG and a waking state.

\section{Discussion}

The concept of the ascending arousal system has been accepted for more than half a century as the basis for understanding the neuronal substrates of consciousness and coma. This model has directed and shaped research on cortical function and sleep-wake regulation, as 
well as clinical evaluation of patients with loss of consciousness (Posner et al., 2007). Our findings challenge some of the most widely accepted components of that model, and suggest that the projection from the $\mathrm{PB} / \mathrm{PC}$ region to the $\mathrm{BF}$ and from there to the cerebral cortex may constitute a critical pathway for maintaining a waking cortical state. Conversely, our evidence suggests that the reticulo-thalamo-cortical pathway that is most often credited with maintaining the waking state may play a lesser role in maintaining waking patterns of EEG, behavior, and cFos expression, at least in rats.

\section{Role of the thalamus vs. BF in the control of cortical arousal}

The functional integrity of the thalamus has been widely considered to be necessary for generating the EEG correlates of cortical arousal and a wakeful state (Steriade et al., 1993; Llinas and Steriade, 2006). It is likely that the thalamus, which transmits a wide range of sensory inputs to the cerebral cortex, is necessary for normal cognitive function. On the other hand, a number of previous studies have reported evidence that the integrity of the thalamus is not necessary to maintain an aroused cortical state in rats or cats (Starlz et al., 1951; Villablanca and Salinas-Zeballos, 1972; Vanderwolf and Stewart, 1988; Buzsaki et al., 1988). Other studies showed that infusion of lidocaine into the BF, but not the reticular or intralaminar thalamic nuclei, strongly attenuated the cortical arousal effects (desynchronized EEG) elicited by electrical stimulation in the PPT region or by tail pinch in urethane-anesthetized rats (Dringenberg and Olmstead, 2003). Injection of procaine into the $\mathrm{BF}$ caused the behavioral and EEG appearances of NREM sleep, whereas injections of the glutamate agonists, either AMPA or NMDA, caused immediate and prolonged wakefulness (Cape and Jones, 2000). These results strongly argue that activating influences from the brainstem may reach the neocortex via an extra-thalamic, BF route.

Despite this evidence, the role of the thalamus in cortical arousal has remained controversial. For example, Buzsaki and colleagues (1988) proposed that low-frequency cortical EEG observed after lesions of the $\mathrm{BF}$ was due to loss of BF projections to both the neocortex and to the thalamus. However, in our experiments the Fos expression (following behavioral stimulation) in the thalamus was comparable in control animals and those with BF lesions, suggesting that the thalamus does not necessarily depend upon the BF for its activation nor was it capable of activating the cortex without the BF input. In this view, the thalamus would transmit specific information that provides the content of the waking state and may therefore contribute to overall arousal if thalamic input demands attention, but the thalamus is neither necessary to produce wakefulness nor sufficient to produce it without the BF.

Because thalamic relay neurons fire in patterns that correlate with cortical EEG (Steriade et al., 1993; Llinas and Steriade, 2006), it is often assumed that the thalamus plays a causal role in entraining the frequency of the EEG. The results of the present study suggest this is not the case for EEG frequencies below $35 \mathrm{~Hz}$ (the upper end of the range that our EEG recordings could measure) because elimination of thalamic inputs does not appear to prevent the normal sleep or wake EEG patterns (with the exception of EEG spindles) in the corresponding cortical areas. It is possible that the thalamus may be critical for driving high frequency cortical rhythms, but this will require further investigation. However, our experiments suggest that it is likely that the correlation between thalamic neuronal firing and the cortical EEG in the $1-35 \mathrm{~Hz}$ range results from cortical activity driving thalamic firing, rather than vice versa. Another possibility is that the small amount of remaining thalamus in our study (mainly lateral and medial geniculate nuclei) could be entraining the visual and auditory cortex, and that these could in turn entrain the EEG rhythms of the entire remaining cortex. We think this possibility is unlikely because current theories of the role of the cortex and the thalamus in the generation of EEG waveforms rely upon the relationship between cortical neurons and their thalamic relay nuclei, which were clearly eliminated for the 
fronto-parietal areas from which we recorded EEG. On the other hand, the dialog between the cortex and the thalamus clearly plays a major role in such features as EEG spindles.

Our results provide strong evidence for the critical role of the BF in sleep-wake behavior and cortical EEG activation. There is an extensive literature demonstrating that neurons in the BF fire in bursts that are time-locked to EEG waves (Lee et al., 2005) and that stimulation of the BF can activate the EEG (Berridge and Foote, 1996; Cape and Jones, 2000), whereas inhibition of BF firing can slow the EEG (Cape and Jones, 2000; Xu et al, 2004). Hence, the BF is a candidate for entraining cortical EEG rhythms in the absence of thalamic activity. Earlier studies had found modest chronic effects on EEG of either limited non-selective BF lesions (Buzsaki et al., 1988; Kaur et al. 2008) or more extensive selective cholinergic BF lesions by using IgG-192-saporin (Berntson et al., 2002; Kapas et al., 1996; Wenk et al., 1994; Blanco-Centurion et al., 2006). In the present study, widespread nonselective cell-specific BF lesions resulted in the loss of EEG components >1Hz EEG, resulting in a rhythm that is similar to isolated cerebral cortex, and the loss of behavioral responsiveness, despite the high state of activity in brainstem, hypothalamic, and thalamic arousal systems as evidenced by Fos activation of key subcortical structures. These findings are in agreement with but extend those of Buzsaki et al (1988) who found unilateral low frequency EEG abnormalities following more limited unilateral BF lesions, and Kaur et al. (2008) who found persistent increases in delta power after relatively small bilateral ibotenic acid lesions killing about $40 \%$ of parvalbumin and $20 \%$ of cholinergic neurons in the caudal basal forebrain.

\section{The PB-PC as a key component of the ascending arousal system}

Many modern reviews (including those we have contributed) emphasize the roles played by the cholinergic and monoaminergic ascending pathways in the arousal system (Datta and Maclean, 2007; Fuller et al, 2006; Saper et al., 2005; Jones, 2003; Siegel, 2004). However, studies in which these different cell groups were selectively damaged with cell-specific toxins have found only minimal changes in wake-sleep amount or EEG activation (see Lu et al., 2006a,b; Blanco-Centurion et al., 2007 for review). The results from the present study identify a single specific and delimited node in the ascending arousal system, the PB-PC, whose participation is absolutely required for maintenance of normal wakefulness. In essence, we propose that the acute loss of wakefulness caused by electrolytic or mechanical lesions in the midbrain reticular formation may be due mainly to disruption of the ascending projections to the $\mathrm{BF}$ from the $\mathrm{PB}-\mathrm{PC}$. While many other cell groups, including the monoaminergic and cholinergic components of the arousal system, may play specific roles in modulating arousal, particularly under specific physiological circumstances, no other brainstem cell population has yet been found to be absolutely necessary to maintain a waking state.

The PB-PC complex is a major, but previously under-appreciated brainstem source of projections to the BF (Fulwiler and Saper, 1984; Moga et al., 1990). In fact, in rats the PB is the largest source of brainstem afferents to the $\mathrm{BF}$ and the $\mathrm{PB}$ projection to the $\mathrm{BF}$ is one of the largest forebrain projections of the PB (Saper and Loewy, 1980; Grove, 1988). The PB$\mathrm{PC}$ also has substantial projections to the intralaminar thalamus, the lateral hypothalamus, and the amygdala (Krout and Loewy, 2000; Munk et al., 1996; Fulwiler and Saper, 1984). In addition, the medial PB is reciprocally connected with the dorsolateral and medial prefrontal and insular cortices (Zaborszky et al., 2005; Saper, 1982, 1984). Thus, the PB/PC has projections to a wide range of forebrain targets that may contribute to wakefulness.

In cats, the PB overlaps spatially with the PPT, and the entire complex is often called the "peribrachial region." Several earlier studies examining single unit recordings in freely moving cats showed that many neurons in the "peribrachial" region are wake-active whereas 
others are REM-active (Gilbert and Lydic, 1990; Sieck and Harper, 1980), suggesting separate populations of neurons in this region controlling brain activation of wakefulness and REM sleep. In rats, the PPT and LDT are spatially differentiated from the PB and PC (respectively) so that the contributions of the two populations can be delineated. Recordings from the PPT and LDT in rats (Datta and Siwek, 2002) support the activity patterns that have been identified in cats (Steriade et al., 1990), but comparable recordings from the PBPC across wake-sleep states are lacking. Given that PPT and LDT lesions cause minimal effects on wake-sleep activity or EEG in rats (Lu et al., 2006b) except when they extend into the PB-PC, such studies are long overdue.

Because our $\mathrm{PB} / \mathrm{PC}$ lesions that caused coma included small but variable amounts of the adjacent LDT, PPT or LC, the question can be raised whether these could have contributed to the loss of wakefulness. However, much more complete lesions of the LC in rats (Lu et al., 2006; Blanco-Centurion et al., 2008) or the PPT and LDT in rats (Lu et al., 2006) or cats (Webster and Jones, 1988; Shouse and Siegel, 1992) have had no major effect on the amount of wakefulness. In the Lu et al. (2006b) study, the small loss of wakefulness with large PPT lesions was seen only in cases that involved the medial PB. We also recognize that other non-cholinergic (i.e., glutamatergic) neurons that are mixed among the cholinergic neurons in the PPT, were damaged by the lesions in the PB/PC that caused coma. However, partial involvement of glutamatergic neurons in the PPT in our experiments is unlikely to account for the loss of wakefulness given that even large lesions of this same cell group, with little damage to the $\mathrm{PB}$, have little or no effect on wakefulness.

In monkeys and humans with high-speed impact head injury, long-lasting coma and persistent vegetative state correlate with hemorrhage in the PB region due to the impact of the free edge of the tentorium on the surface of the pons (Kampf et al., 1998; Adams et al., 1982; Shigermori et al., 1992; Blumbergs et al., 1989; Gennarelli et al., 1982). By contrast, cell-specific lesions confined to the pontine reticular formation in animals never induce coma (Denoyer et al., 1991; Lu et al., 2006b). On the other hand, damage to axons traversing the brainstem along the route of the ascending fibers from the PB-PC (Saper and Loewy, 1980) causes coma in animals and humans (Parvizi and Damasio, 2003; Lindsely et al., 1949), and electrical stimulation along this route desynchronizes cortical EEG (Moruzzi and Magoun, 1949).

Another behavioral state that may be explained by the PB-PC activity profile is peduncular hallucinosis. In this puzzling condition, patients with lesions of the mesopontine tegmentum have dream-like states with intense and very active visual experiences, against a waking background (Manford and Andermann, 1998). Our previous study found that there is intense GABAergic inhibitory input to the PB-PC from the REM-off area in the lateral pontine tegmentum and ventrolateral periaqueductal gray matter (Lu et al., 2006b). We hypothesize that lesions of the REM-off neurons that inhibit the PB-PC may disinhibit patterns of neuronal firing that normally occur only during REM sleep, thus producing dream-like states at inappropriate times. A similar mechanism may explain hypnagogic (while falling asleep) and hypnopompic (while awakening) hallucinations, which occur most commonly in patients with narcolepsy, but are sometimes seen in healthy young adults who have been sleep deprived.

\section{Is the PB-PC a component of the wake-sleep switching system?}

We have previously proposed that a mutually inhibitory interaction between sleep-active neurons of the ventrolateral preoptic nucleus (VLPO) and monoaminergic arousal systems regulates sleep-wake behavior (see Saper et al., 2005). The central lateral PB subnucleus is also a major source of inputs to the VLPO (Chou et al., 2002), and the VLPO sends a return projection that innervates the entire PB-PC complex to about the same extent as the adjacent 
LC (Sherin et al., 1998). Hence, the PB-PC may be an important part of the flip-flop switch that has been proposed to regulate wake-sleep transitions (Saper et al., 2005). On the other hand, PB-PC neurons that project to the BF should be active during both wakefulness and REM sleep. In the presence of concomitant activation of the monoaminergic arousal systems (Saper et al., 2005), the cortical response to PB/PC-BF activation would be wakefulness; in the absence of monoaminergic stimulation, a state of REM sleep would prevail. In this model, monoaminergic and cholinergic systems may modulate the activity of the PB-PC, and can determine (via their cortical and thalamic projections) whether the PB-PC induces wakefulness vs. REM sleep, but they cannot sustain a waking (or REM) state without the PB-PC.

\section{Acknowledgments}

This work was supported by the National Institutes of Health HL60292, AG09775, HL095491, and the Harold G. and Leila Y. Mathers Foundation.

The authors thank Quan Ha for excellent technical work and Ramalingam Vetrivelan for helpful discussion.

\section{Abbreviations in text and figures}

DAB

BF

$\mathrm{CPu}$

CTb

ChAT

DB

DRN

DTg

EMG

EEG

IVv

GP

IC

LG

LPB

LPT

LS

LDT

LC

MBN

MCPO

MPB

MPRF 3,3-diaminobenzidine tetrahydrochloride

basal forebrain

caudate-putamen

cholera toxin subunit B

choline acetyltransferase

diagonal band nucleus

dorsal raphe nucleus

dorsal tegmental nucleus

electromyogram

electroencephlogram

fourth ventricle

globus pallidus

internal capsule

lateral geniculate nucleus

lateral parabrachial nucleus

lateral pontine tegmentum

lateral septal nucleus

laterodorsal tegmental nucleus

locus coeruleus

magnocellular basal nucleus

magnoceullar preoptic nucleus

medial parabrachial nucleus

medial pontine reticular formation 
MPO medial preoptic nucleus

MS

MnR

MD

MNV

NREM

OC

OT

OX-SAP

PB

PF

PVH

PPT

PBS

PnC

PnO

PC

REM

RT

SLD

SI

scp

TH

VA

vIPAG

VLPO

VGLUT2 medial septum

median raphe nucleus

mediodorsal thalamic nucleus

mesencephalic trigeminal nucleus

non-rapid eye movement sleep

optic chiasm

optic tract

orexin-saporin

parabrachial nucleus

parafascicular thalamic nucleus

paraventricular nucleus of the hypothalamus

pedunculopontine tegmental nucleus

phosphate buffered saline

pontine reticular nucleus, caudal

pontine reticular nucleus, oral

precoeruleus area

rapid eye movement sleep

reticular thalamic nucleus

sublaterodoral nucleus

substantia innominata

superior cerebellar peduncle

tyrosine hydroxylase

ventroanterior thalamic nucleus

ventrolateral periaqueductal gray matter

ventrolateral preoptic nucleus

vesicular glutamate 2 transporter

\section{Literature Cited}

Adametz JH. Rate of recovery of functioning in cats with rostral reticular lesions; an experimental study. J Neurosurg. 1959; 16:85-97. [PubMed: 13621267]

Adams JH, Graham DI, Murray LS, Scott G. Diffuse axonal injury due to nonmissile head injury in humans: an analysis of 45 cases. Ann Neurol. 1982; 12:557-63. [PubMed: 7159059]

Batini C, Moruzzi G, Palestini M, Rossi GF, Zanchetti A. Effects of complete pontine transections on the sleep-wakefulness rhythm: the midpontine pretri-geminal preparation. Arch Ital Biol. 1959; 97:1-12.

Berntson GG, Shafi R, Sarter M. Specific contributions of the basal forebrain corticopetal cholinergic system to electroencephalographic activity and sleep/waking behaviour. Eur J Neurosci. 2002; 16:2453-61. [PubMed: 12492440] 
Berridge CW, Foote SL. Enhancement of behavioral and electroencephalographic indices of waking following stimulation of noradrenergic beta-receptors within the medial septal region of the basal forebrain. J Neurosci. 1996; 16:6999-7009. [PubMed: 8824336]

Blanco-Centurion C, Xu M, Murillo-Rodriguez E, Gerashchenko D, Shiromani AM, Salin-Pascual RJ, Hof PR, Shiromani PJ. Adenosine and sleep homeostasis in the basal forebrain. J Neurosci. 2006; 26:8092-100. [PubMed: 16885223]

Blanco-Centurion C, Gerashchenko D, Shiromani PJ. Effects of saporin-induced lesions of three arousal populations on daily levels of sleep and wake. J Neurosci. 2007; 27(51):14041-8. [PubMed: 18094243]

Blumbergs PC, Jones NR, North JB. Diffuse axonal injury in head trauma. J Neurol Neurosurg Psychiatry. 1989; 52:838-41. [PubMed: 2769276]

Bremer F. Cerveau isole et physiologie du sommeil. CR Soc Biol (Paris). 1935; 118:1235-1242.

Buzsaki G, Bickford RG, Ponomareff G, Thal LJ, Mandel R, Gage FH. Nucleus basalis and thalamic control of neocortical activity in the freely moving rat. J Neurosci. 1998; 8:4007-26. [PubMed: 3183710]

Cape EG, Jones BE. Effects of glutamate agonist versus procaine microinjections into the basal forebrain cholinergic cell area upon gamma and theta EEG activity and sleep-wake state. Eur J Neurosci. 2000; 12(6):2166-84. [PubMed: 10886356]

Chen CT, Dun SL, Kwok EH, Dun NJ, Chang JK. Orexin A-like immunoreactivity in the rat brain. Neurosci Lett. 1999; 260:161-164. [PubMed: 10076892]

Chou TC, Bjorkum AA, Gaus SE, Lu J, Scammell TE, Saper CB. Afferents to the ventrolateral preoptic nucleus. J Neurosci. 2002; 22:977-90. [PubMed: 11826126]

Chou TC, Scammell TE, Gooley JJ, Gaus SE, Saper CB, Lu J. Critical role of dorsomedial hypothalamic nucleus in a wide range of behavioral circadian rhythms. J Neurosci. 2003; 23(33): 10691-702. [PubMed: 14627654]

Datta S, Hobson JA. Suppression of ponto-geniculo-occipital waves by neurotoxic lesions of pontine caudo-lateral peribrachial cells. Neuroscience. 1995; 67(3):703-12. [PubMed: 7675196]

Datta S, Siwek DF. Single cell activity patterns of pedunculopontine tegmentum neurons across the sleep-wake cycle in the freely moving rats. J Neurosci Res. 2002; 70:611-21. [PubMed: 12404515]

Datta S, Maclean RR. Neurobiological mechanisms for the regulation of mammalian sleep-wake behavior: reinterpretation of historical evidence and inclusion of contemporary cellular and molecular evidence. Neurosci Biobehav Rev. 2007; 31:775-824. [PubMed: 17445891]

Denoyer M, Sallanon M, Buda C, Kitahama K, Jouvet M. Neurotoxic lesion of the mesencephalic reticular formation and/or the posterior hypothalamus does not alter waking in the cat. Brain Res. 1991; 539:287-303. [PubMed: 1675907]

Dringenberg HC, Olmstead MC. Integrated contributions of basal forebrain and thalamus to neocortical activation elicited by pedunculopontine tegmental stimulation in urethane-anesthetized rats. Neuroscience. 2003; 119:839-53. [PubMed: 12809705]

Ericson H, Blomqvist A. Tracing of neuronal connections with cholera toxin subunit B: light and electron microscopic immunohistochemistry using monoclonal antibodies. J Neurosci Meth. 1988; 24:225-235.

Fuller PM, Gooley JJ, Saper CB. Neurobiology of the sleep-wake cycle: sleep architecture, circadian regulation, and regulatory feedback. J Biol Rhythms. 2006; 21:482-93. [PubMed: 17107938]

Fulwiler CE, Saper CB. Subnuclear organization of the efferent connections of the parabrachial nucleus in the rat. Brain Res. 1984; 319:229-59. [PubMed: 6478256]

Gennarelli TA, et al. Diffuse axonal injury and traumatic coma in the primate. Ann Neurol. 1982; 12:564-74. [PubMed: 7159060]

Gerashchenko D, Kohls MD, Greco M, Waleh NS, Salin-Pascual R, Kilduff TS, Lappi DA, Shiromani PJ. Hypocretin-2-saporin lesions of the lateral hypothalamus produce narcoleptic-like sleep behavior in the rat. J Neurosci. 2001; 21:7273-83. [PubMed: 11549737]

Gilbert KA, Lydic R. Parabrachial neuron discharge in the cat is altered during the carbachol-induced REM sleep-like state (DCarb). Neurosci Lett. 1990; 120:241-4. [PubMed: 2293110] 
González-Cuello A, Milanés MV, Laorden ML. Increase of tyrosine hydroxylase levels and activity during morphine withdrawal in the heart. Eur J Pharmacol. 2004; 506(2):119-28. [PubMed: 15588731]

Gooley JJ, Schomer A, Saper CB. The dorsomedial hypothalamic nucleus is critical for the expression of food-entrainable circadian rhythms. Nat Neurosci. 2006; 9(3):398-407. [PubMed: 16491082]

Greco MA, Fuller PM, Jhou TC, Martin-Schild S, Zadina JE, Hu Z, Shiromani P, Lu J. Opioidergic projections to sleep-active neurons in the ventrolateral preoptic nucleus. Brain Res. 2008; 1245:96-107. [PubMed: 18840417]

Grove EA. Neural associations of the substantia innominata in the rat: afferent connections. J Comp Neurol. 1988; 277:315-46. [PubMed: 2461972]

Hasenstaub A, Shu Y, Haider B, Kraushaar U, Duque A, McCormick DA. Inhibitory postsynaptic potentials carry synchronized frequency information in active cortical networks. Neuron. 2005; 47:423-35. [PubMed: 16055065]

Jones BE. Arousal systems. Front Biosci. 2003; 8:s438-51. [PubMed: 12700104]

Jones BE, Cuello AC. Afferents to the basal forebrain cholinergic cell area from pontomesencephalic —catecholamine, serotonin, and acetylcholine—neurons. Neuroscience. 1989; 31:37-61. [PubMed: 2475819]

Jones BE, Yang TZ. The efferent projections from the reticular formation and the locus coeruleus studied by anterograde and retrograde axonal transport in the rat. 1985; 242:56-92.

Kampfl A, et al. The persistent vegetative state after closed head injury: clinical and magnetic resonance imaging findings in 42 patients. J Neurosurg. 1998; 88:809-16. [PubMed: 9576247]

Kapas L, Obal F Jr, Book AA, Schweitzer JB, Wiley RG, Krueger JM. The effects of immunolesions of nerve growth factor-receptive neurons by 192 IgG-saporin on sleep. Brain Res. 1996; 712:53-9. [PubMed: 8705307]

Kaur S, Junek A, Black MA, Semba K. Effects of ibotenate and 192IgG-saporin lesions of the nucleus basalis magnocellularis/substantia innominata on spontaneous sleep and wake states and on recovery sleep after sleep deprivation in rats. J Neurosci. 2008; 28(2):491-504. [PubMed: 18184792]

Krout KE, Loewy AD. Parabrachial nucleus projections to midline and intralaminar thalamic nuclei of the rat. J Comp Neurol. 2000; 428:475-94. [PubMed: 11074446]

Lee MG, Hassani OK, Alonso A, Jones BE. Cholinergic basal forebrain neurons burst with theta during waking and paradoxical sleep. J Neurosci. 2005; 25:4365-9. [PubMed: 15858062]

Lee MG, Manns ID, Alonso A, Jones BE. Sleep-wake related discharge properties of basal forebrain neurons recorded with micropipettes in head-fixed rats. J Neurophysiol. 2004; 92:1182-9. [PubMed: 15028746]

Lindsley DB, Bowden J, Magoun HW. Effect upon the EEG of acute injury to the brain stem activating system. Electroencephalogr Clin Neurophysiol. 1949; 1:475-486. [PubMed: 18421836]

Llinas RR, Steriade M. Bursting of thalamic neurons and states of vigilance. J Neurophysiol. 2006; 95:3297-3308. [PubMed: 16554502]

Lu J, Bjorkum AA, Xu M, Gaus SE, Shiromani PJ, Saper CB. Selective activation of the extended ventrolateral preoptic nucleus during rapid eye movement sleep. J Neurosci. 2002; 22:4568-76. [PubMed: 12040064]

Lu J, Greco MA, Shiromani P, Saper CB. Effect of lesions of the ventrolateral preoptic nucleus on NREM and REM sleep. J Neurosci. 2000; 20:3830-42. [PubMed: 10804223]

Lu J, Jhou TC, Saper CB. Identification of wake-active dopaminergic neurons in the ventral periaqueductal gray matter. J Neurosci. 2006a; 26:193-202. [PubMed: 16399687]

Lu J, Nelson LE, Franks N, Maze M, Chamberlin NL, Saper CB. Role of endogenous sleep-wake and analgesic systems in anesthesia. J Comp Neurol. 2008; 508:648-662. [PubMed: 18383504]

Lu J, Sherman D, Devor M, Saper CB. A Putative Flip-Flop Switch for Control of REM Sleep. Nature. 2006b; 441:589-594. [PubMed: 16688184]

Manford M, Andermann F. Complex visual hallucinations. Clinical and neurobiological insights. Brain. 1998; 121:1819-40. [PubMed: 9798740] 
Marcus JN, Aschkenasi CJ, Lee CE, Chemelli RM, Saper CB, Yanagisawa M, Elmquist JK. Differential expression of orexin receptors 1 and 2 in the rat brain. J Comp Neurol. 2001; 435:625. [PubMed: 11370008]

Moga MM, Herbert H, Hurley KM, Yasui Y, Gray TS, Saper CB. Organization of cortical, basal forebrain, and hypothalamic afferents to the parabrachial nucleus in the rat. J Comp Neurol. 1990; 295:624-61. [PubMed: 1694187]

Moruzzi G, Magoun H. Brain stem reticular formation and activation othe EEG. Electroencephalogr Clin Neurophysiol. 1949; 1:455-473. [PubMed: 18421835]

Munk MH, Roelfsema PR, Konig P, Engel AK, Singer W. Role of reticular activation in the modulation of intracortical synchronization. Science. 1996; 272:271-4. [PubMed: 8602512]

Nauta WJH. Hypothalamic regulation of sleep in rats. An experimental study. J Neurophysiol. 1946; 9:285-314. [PubMed: 20991815]

Nauta, WJH.; Kuypers, HGJM. Some ascending pathways in the brainstem reticular formation. In: Jasper, H., editor. The Reticular Formation of the Brain. Little Brown; Boston: 1958. p. 3-30.

Parvizi J, Damasio AR. Neuroanatomical correlates of brainstem coma. Brain. 2003; 126:1524-36. [PubMed: 12805123]

Posner, JB.; Saper, CB.; Schiff, ND.; Plum, F. Diagnosis of Stupor and Coma. 4. Oxford Univ Press; New York: 2007. p. 29-34.

Ranson SW. Somnolence caused by hypothalamic lesions in monkeys. Arch Neurol Psychiatr. 1939; 41:1-23.

Saper CB. Reciprocal parabrachial-cortical connections in the rat. Brain Res. 1982; 242(1):33-40. [PubMed: 7104731]

Saper CB. Organization of cerebral cortical afferent systems in the rat. II. Magnocellular basal nucleus. J Comp Neurol. 1984; 222 :313-42. [PubMed: 6699210]

Saper CB, Scammell TE, Lu J. Hypothalamic regulation of sleep and circadian rhythms. Nature. 2005; 437:1257-63. [PubMed: 16251950]

Saper CB. Organization of cerebral cortical afferent systems in the rat. II. Hypothalamocortical projections. J Comp Neurol. 1985; 237:21-46. [PubMed: 2995455]

Saper CB, Loewy AD. Efferent connections of the parabrachial nucleus in the rat. Brain Res. 1980; 197:291-317. [PubMed: 7407557]

Sherin JE, Elmquist JK, Torrealba F, Saper CB. Innervation of histaminergic tuberomammillary neurons by GABAergic and galaninergic neurons in the ventrolateral preoptic nucleus of the rat. $\mathrm{J}$ Neurosci. 1998; 18:4705-21. [PubMed: 9614245]

Shigemori M, et al. Coexisting diffuse axonal injury (DAI) and outcome of severe head injury. Acta Neurochir Suppl (Wien). 1992; 55:37-9. [PubMed: 1414542]

Shouse MN, Siegel JM. Pontine regulation of REM sleep components in cats: integrity of the pedunculopontine tegmentum (PPT) is important for phasic events but unnecessary for atonia during REM sleep. Brain Res. 1992; 571(1):50-63. [PubMed: 1611494]

Sieck GC, Harper RM. Discharge of neurons in the parabrachial pons related to the cardiac cycle: changes during different sleep-waking states. Brain Res. 1980; 199:385-99. [PubMed: 7417790]

Siegel J. Brain mechanisms that control sleep and waking. Naturwissenschaften. 2004; 8:355-65. [PubMed: 15278215]

Sinton CM, McCarley RW. Neurophysiological mechanisms of sleep and wakefulness: a question of balance. Semin Neurol. 2004; 24:211-23. [PubMed: 15449215]

Smith HR, Pang KC. Orexin-saporin lesions of the medial septum impair spatial memory. Neuroscience. 2005; 132(2):261-71. [PubMed: 15802181]

Starzl TE, Taylor CW, Magoun HW. Ascending conduction in reticular activating system, with special reference to the diencephalon. J Neurophysiol. 1951; 14:461-77. [PubMed: 14889301]

Steriade M, Datta S, Pare D, Oakson G, Curro Dossi RC. Neuronal activation in brain-stem cholinergic nuclei related to tonic activation processes in thalamocortical systems. J Neurosci. 1990; 10:254159. [PubMed: 2388079] 
Steriade M, Dossi RC, Pare D, Oakson G. Fast oscillations (20-40 Hz) in thalamocortical systems and their potentiation by mesopontine cholinergic nuclei in the cat. Proc Natl Acad Sci. 1991; 88:4396-400. [PubMed: 2034679]

Steriade M, McCormick DA, Sejnowski TJ. Thalamocortical oscillations in the sleeping and aroused brain. Science. 1993; 262:679-85. [PubMed: 8235588]

Thompson RH, Swanson LW. Structural characterization of a hypothalamic visceromotor pattern generator network. Brain Res Brain Res Rev. 2003; 41:153-202. [PubMed: 12663080]

Vanderwolf CH, Stewart DJ. Thalamic control of neocortical activation: a critical re-evaluation. Brain Res Bull. 1998; 20:529-38. [PubMed: 3395864]

Villablanca J, Salinas-Zeballos ME. Sleep-wakefulness, EEG and behavioral studies of chronic cats without the thalamus: the 'athalamic' cat. Arch Ital Biol. 1972; 110:383-411. [PubMed: 4349191]

Webster HH, Jones BE. Neurotoxic lesions of the dorsolateral pontomesencephalic tegmentumcholinergic cell area in the cat. II. Effects upon sleep-waking states. Brain Res. 1988; 458(2):285302. [PubMed: 2905197]

Wenk GL, Stoehr JD, Quintana G, Mobley S, Wiley RG. Behavioral, biochemical, histological, and electrophysiological effects of $192 \mathrm{IgG}$-saporin injections into the basal forebrain of rats. $\mathrm{J}$ Neurosci. 1994; 14:5986-95. [PubMed: 7523630]

Xu C, Datta S, Wu M, Alreja M. Hippocampal theta rhythm is reduced by suppression of the H-current in septohippocampal GABAergic neurons. Eur J Neurosci. 2004; 19:2299-309. [PubMed: 15090056]

Yokota S, Oka T, Tsumori T, Nakamura S, Yasui Y. Glutamatergic neurons in the Kolliker-Fuse nucleus project to the rostral ventral respiratory group and phrenic nucleus. A combined retrograde tracing and in situ hybridization study in the rat. Neurosci Res. 2007; 59:342-346.

Zaborszky L, et al. Three-dimensional chemoarchitecture of the basal forebrain: Spatially specific association of cholinergic and calcium binding protein-containing neurons. Neuroscience. 2005; 136:697-713. [PubMed: 16344145] 
Thalamus lesion
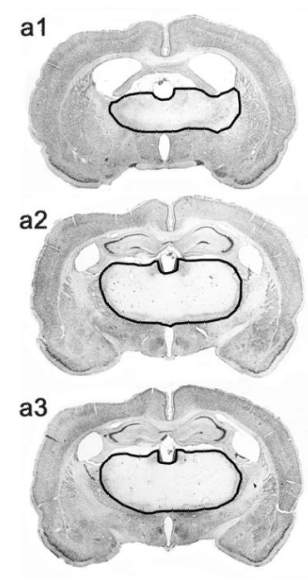

a4

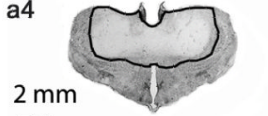

b

C
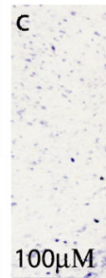
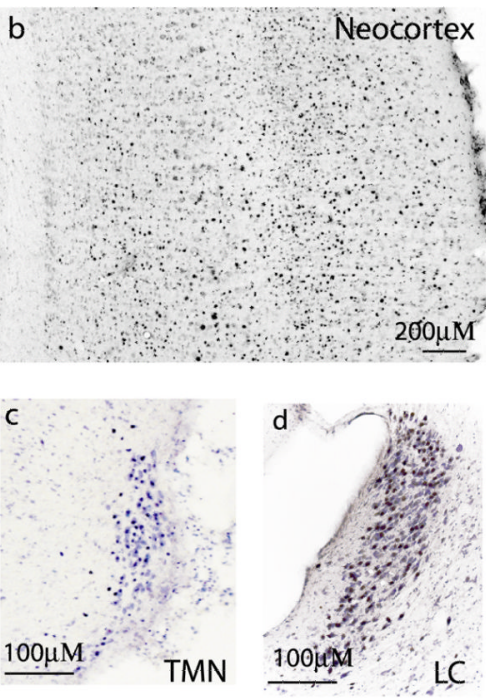
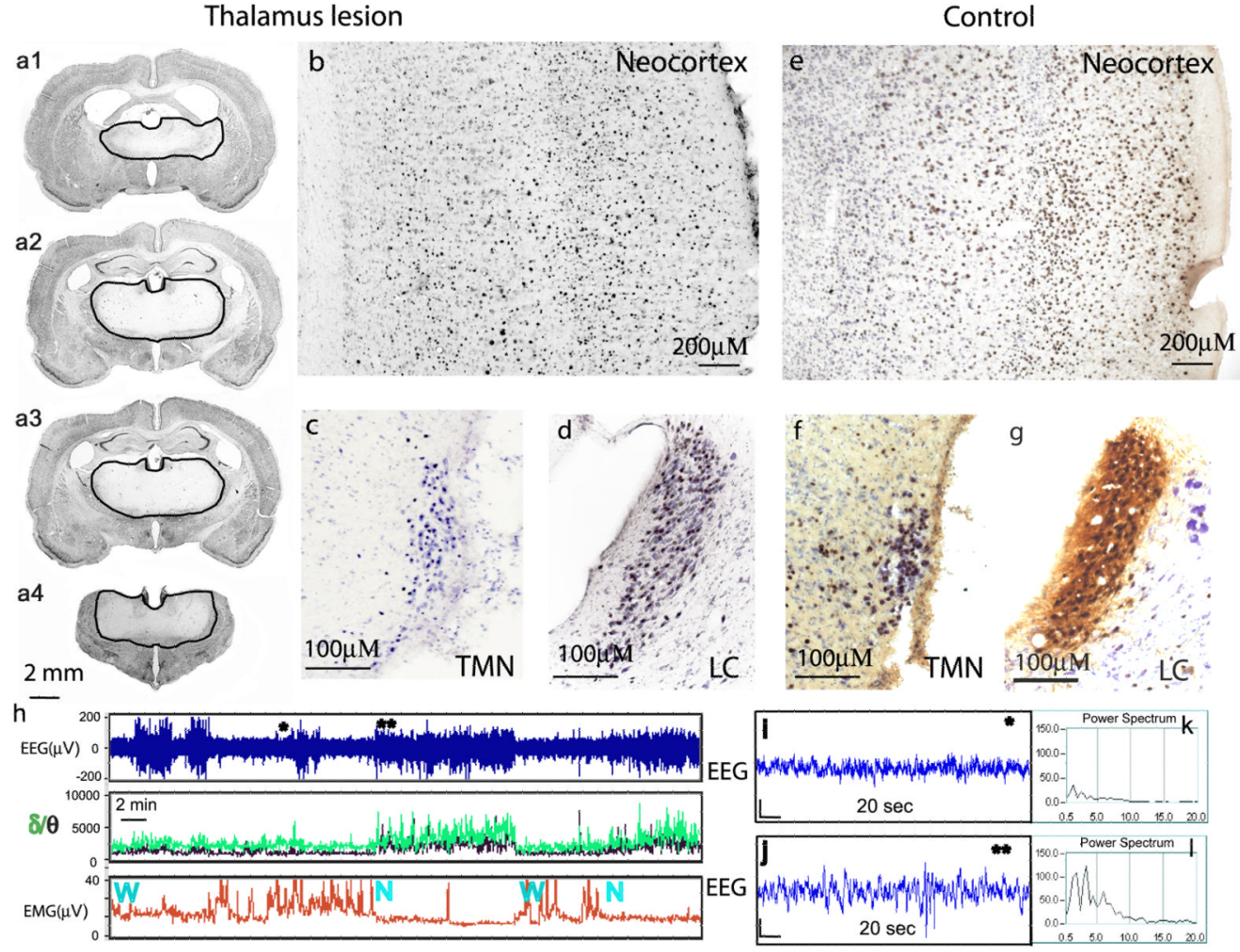

Figure 1.

Effects of ibotenic acid lesions of the thalamus on arousal-induced Fos expression and cortical EEG. (a) A series of sections through the thalamus of one rat (R3598) from rostral to caudal levels demonstrating the typical extensive lesion (demarcated by black line), sparing only the most lateral part of the ventroposterior complex, lateral and medial geniculate nuclei, and parts of the reticular nucleus. Fos expression (black nuclei) in the neocortex (b), the TMN (c) and LC (d) in R3598 after $2 \mathrm{hr}$ of behavioral arousal was similar to that seen in a control rat (e-g; brown stain in $\mathrm{g}$ is tyrosine hydroxylase immunohistochemistry). Panels h-l demonstrate the sleep-wake physiology of a rat sustaining a full thalamic lesion. (h) The EEG (top panel) and EMG (bottom panel) traces from such a rat during a 30 minute period containing both wake $(\mathrm{W})$ and NREM sleep $(\mathrm{N})$ bouts. The middle panel in (h) shows the relative magnitude and changes in delta $(\delta$; green trace) and theta ( $\theta$; black trace) power during this recording window. Panels $i$ and $j$ show representative 20-sec EEG epochs and $\mathrm{k}$ and 1 demonstrate the associated power spectra from an athalamic rat during wakefulness* $(\mathrm{i}, \mathrm{k})$ and sleep** $(\mathrm{j}, \mathrm{l})$. In these power spectra and the ones that follow, EEG power is shown on the y axis in arbitrary units, and the frequency band $(\mathrm{Hz})$ on the $\mathrm{x}$-axis. Scale bar for $\mathrm{i}$ and $\mathrm{j}=80 \mu \mathrm{V}$. 


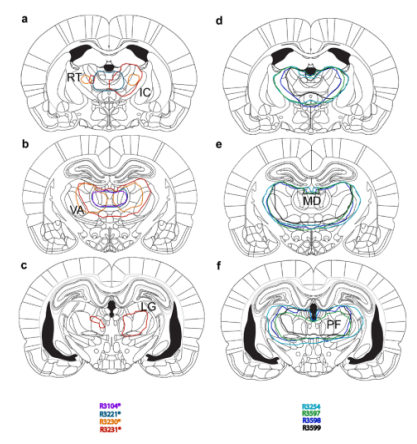

Figure 2.

Cell-body specific lesions were placed in the rat thalamus by injecting ibotenic acid bilaterally. The extent of the lesions in eight rats are shown, including four rats (R3254, R3597, R3598, R3599) with the most extensive lesions and four rats with less extensive lesions (R3104, R3221, R3230, and R3231, marked by asterisk, *). The four rats with the most extensive lesions (typically sparing only the most lateral part of the ventroposterior complex, lateral and medial geniculate nuclei, and parts of the reticular nucleus) were used in the analysis. Remarkably, rats sustaining even the most extensive thalamic lesions evidenced minimal changes in sleep-wake physiology. 

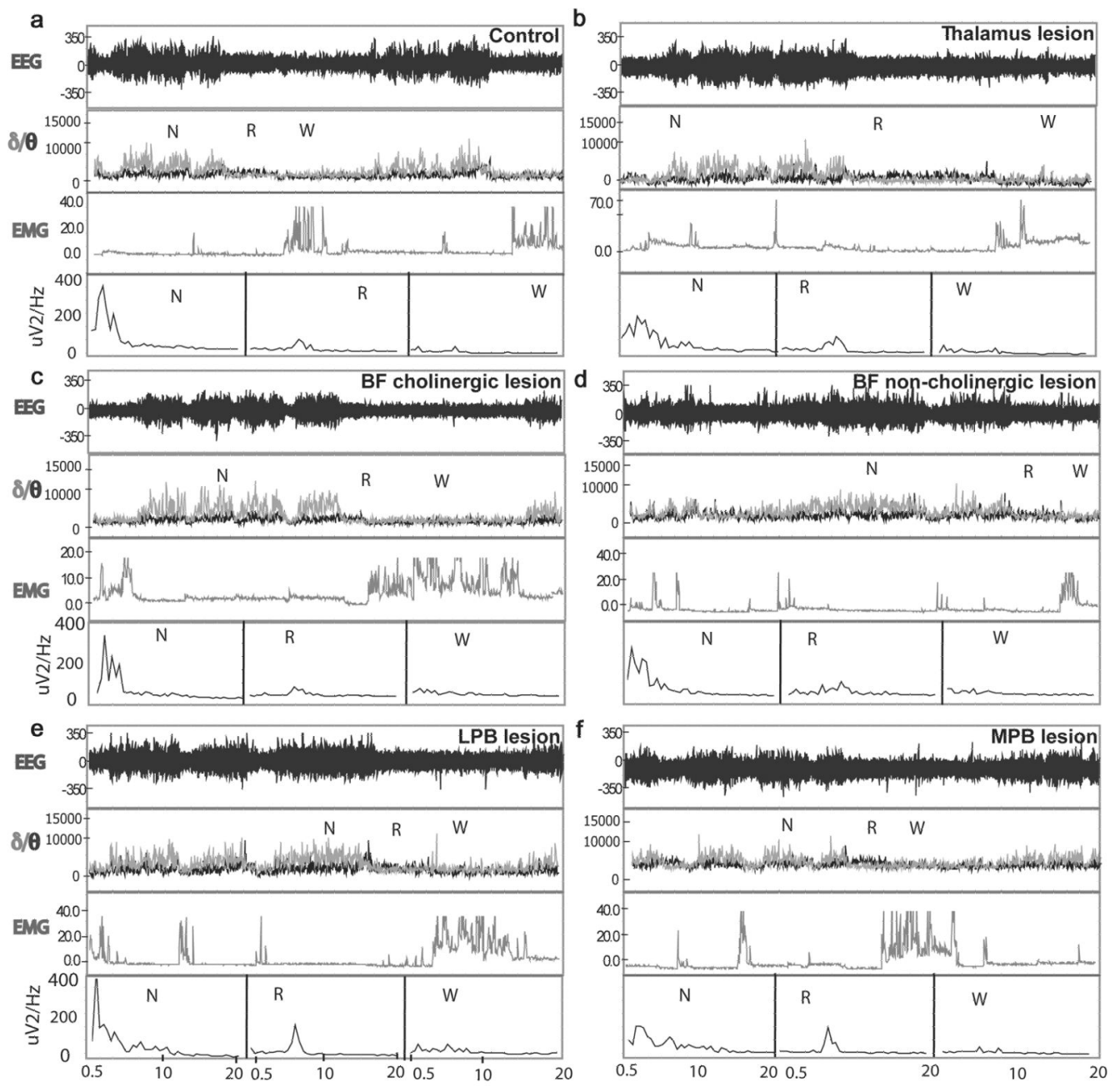

Figure 3.

Effects of cell-body selective lesions of the thalamus, BF cholinergic and non-cholinergic neurons, and the lateral and medial PB on the NREM, REM and waking EEG and associated power spectra. Panel a shows the sleep-wake EEG and associated power spectrum from an unlesioned rat. The remaining panels show the sleep-wake EEG and associated power spectrum from rats sustaining lesions of the (b) thalamus, (c) cholinergic BF neurons, (d) non-cholinergic BF neurons, (e) lateral parabrachial nucleus and (f) medial parabrachial nucleus. The power spectra in each state from the lesioned animals exhibit remarkably little difference from the unlesioned controls shown in Panel a. By contrast, combined cholinergic and non-cholinergic MBN lesions and complete PB-PC lesions produced a monotonous EEG with frequencies in the sub-delta range (cf. Panel a and Fig 5. f-g and Fig10. j-l). 

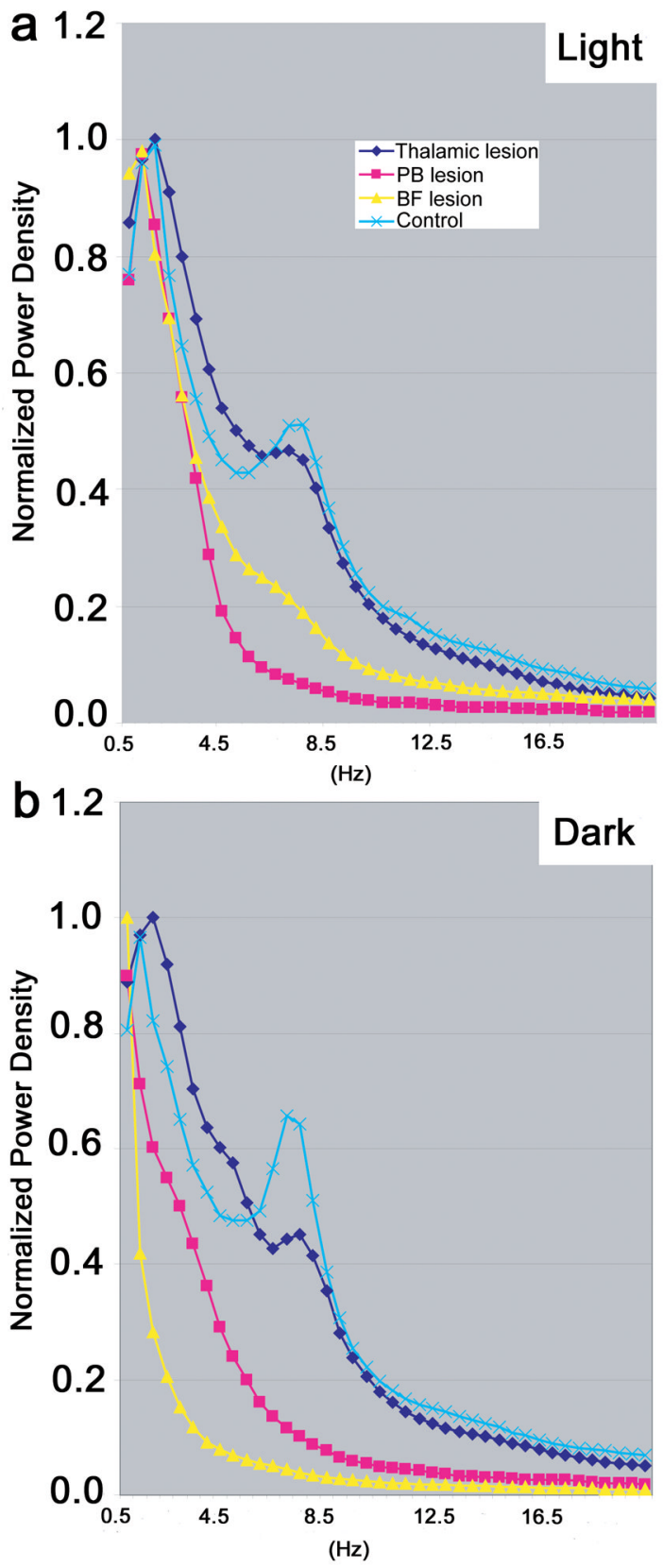

Figure 4.

Normalized power spectra across 12 hours during either the light period (a) or the dark period (b) in control rats and ones with lesions of the thalamus (Tha), basal forebrain (BF), or parabrachial nucleus (PB). Note that the thalamic lesions caused only a loss of theta power, which was most marked during the dark period. The basal forebrain and parabrachial lesions caused extensive loss of EEG activity above the frequency of $1 \mathrm{~Hz}$, with very little remaining EEG power above $4 \mathrm{~Hz}$ (i.e., above the delta range). 

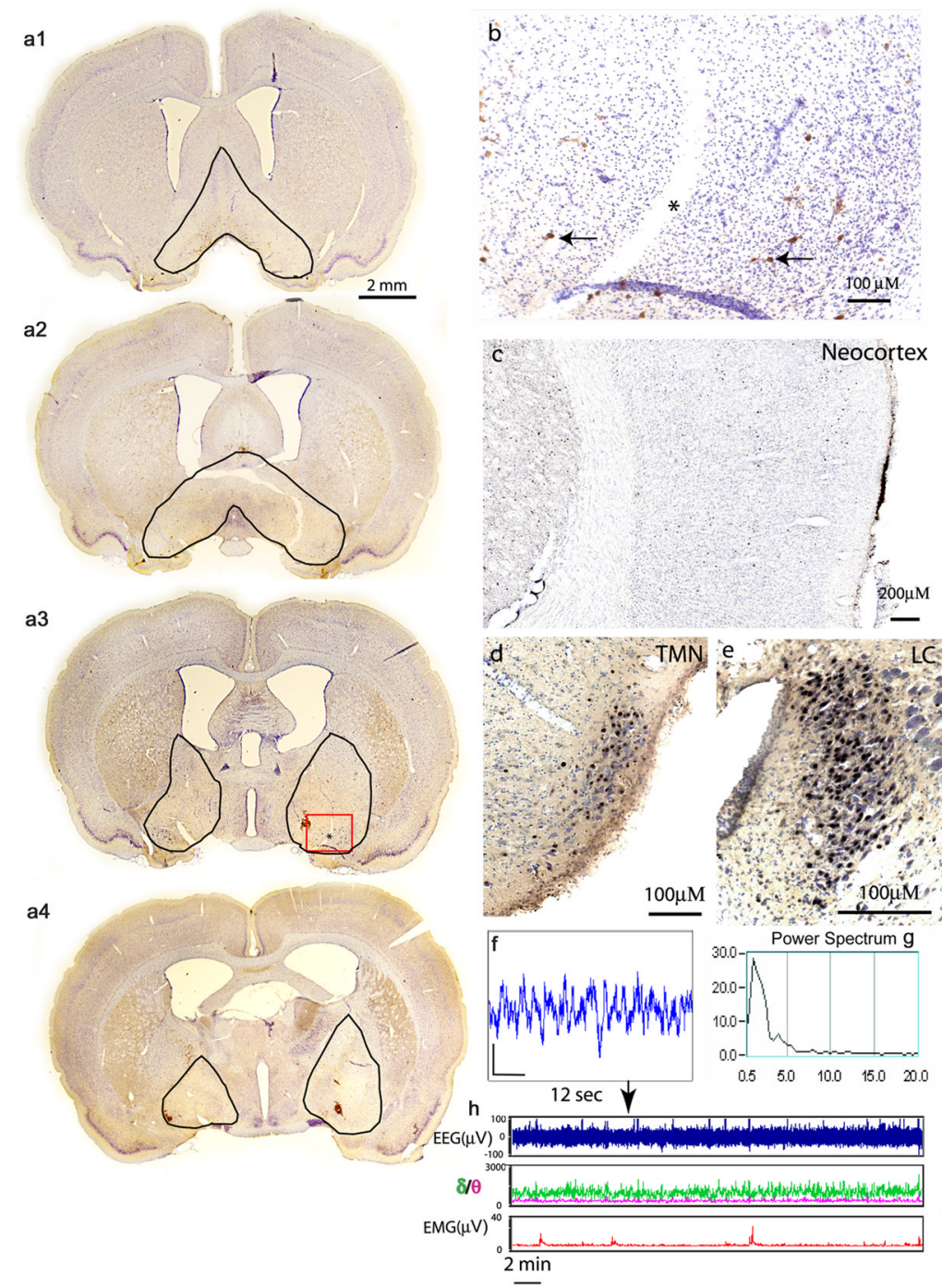

Figure 5.

Effects of non-selective lesions of the BF on the EEG pattern and Fos expression induced by continuous stimulation (gentle touching). In (a1-a4), a series of sections (stained immunohistochemically, brown, for ChAT, with a blue thionin counterstain) is shown arranged in rostro-caudal order through the BF in a rat with bilateral lesions using orexinsaporin (125 ng total), which killed $88 \%$ of the cholinergic neurons and virtually all noncholinergic neurons in the BF. (b) An enlarged view of the area in the red box in (a3). Note that in the center of the lesion field (upper part of panel $b$ ) there are few if any surviving neurons remaining, whereas in the lower part of the panel, at the edge of the lesion area, about a dozen cholinergic cells (arrows) are the only surviving neurons in the field, which is otherwise filled with small glial nuclei. (c) Neocortical Fos expression after two-hours of sensory stimulation. A low level of Fos expression was seen in the neocortex, despite elevated Fos activity in the TMN (d) and the LC (e). (f) EEG following BF ablation (i.e., during the coma-like state) demonstrated monotonous $<1.0 \mathrm{~Hz}$ oscillation across all behaviors. The left panel (f) shows $12 \mathrm{sec}$ of EEG (at the time indicated by the arrow in panel $\mathrm{h}$ ) and the right panel (g) shows a power spectrum for this $12 \mathrm{sec}$ period. Note that the only peak is in the sub-delta range. Panel (h) shows $20 \mathrm{~min}$ of EEG/EMG in this behaviorally unresponsive state. Note that the delta power (green) remains uniformly high 
and the theta power (magenta) low, even during brief abortive movements (spikes in the EMG trace). Scale bars in $\mathrm{f}=2 \mathrm{sec}$ (horizontal), $50 \mu \mathrm{V}$ (vertical). 


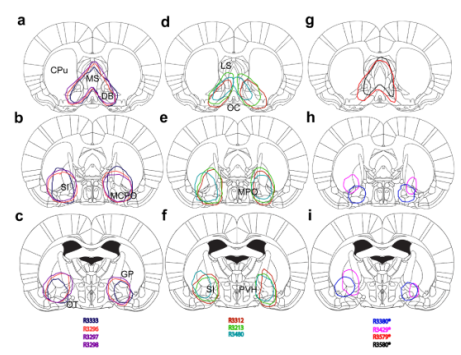

Figure 6.

Cell-body specific lesions were placed in the rat basal forebrain by injecting either IgG192saporin or orexin-saporin into the MCPO, SI and MS. The extent of the lesions in eleven rats are shown, including seven rats (R3312, R3213, R3333, R3296, R3297, R3298, R3480) with the most extensive lesions and four rats (marked by asterisk, *) with less extensive lesions (R3380, R3429, R3579, R3580). The seven rats with the most extensive lesions demonstrated near complete loss of cholinergic and non-cholinergic neurons in the MBN and all exhibited a coma-like state. The four rats sustaining less extensive lesions did not exhibit a similar coma-like state. 


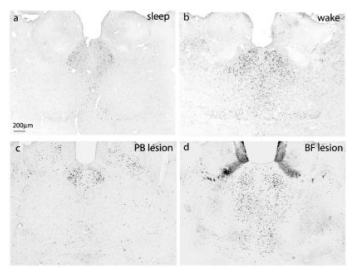

Figure 7.

Fos expression in the midline thalamus following natural sleep (a) or active waking (b), in a control rat, or following sensory stimulation during the coma-like state in rats with bilateral PB-PC (c) or BF lesions (d). Note that although both the BF and PB-PC lesions produced a similar coma-like state, the BF lesion did not prevent activation of the midline thalamic nuclei during sensory stimulation, whereas the $\mathrm{PB} / \mathrm{PC}$ lesion did prevent this activation. These results suggest that the PB-PC complex but not the BF drives thalamic activation under normal conditions. 


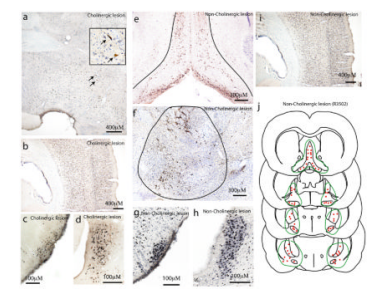

Figure 8.

Effects of selective lesions of cholinergic neurons or non-cholinergic neurons in the BF on cortical arousal. Intraventricular injections of $192 \mathrm{IgG}$-saporin $(1 \mu \mathrm{g})$ killed more than $95 \%$ of BF cholinergic neurons shown by ChAT immunohistochemistry (brown). Only a few remaining ChAT-positive neurons were seen (a, arrows; see inset for higher power view of area just dorsal to arrows and showing brown, ChAT-positive neurons). In these animals, high levels of Fos immunoreactivity was induced in remaining neurons in the BF (a), as well as in the neocortex (b), the TMN (c), and the LC (d) following two-hours of behavioral stimulation. Lesions caused by lower dose injections of OX-SAP (100 ng total) spared most cholinergic neurons (stained brown for ChAT) but killed almost all other cells in the BF (ef). The black lines outline the extent of the lesion, and there are few remaining large blue (non-cholinergic) neurons in the lesion area in these thionin counterstained sections. These animals also showed high levels of Fos in the TMN (g), the LC (h) and the neocortex (i) after behavioral arousal. The region of the lesion in one of these animals is shown by the green line in (j), and the locations of surviving cholinergic neurons by red dots (one dot $=12$ cells). 


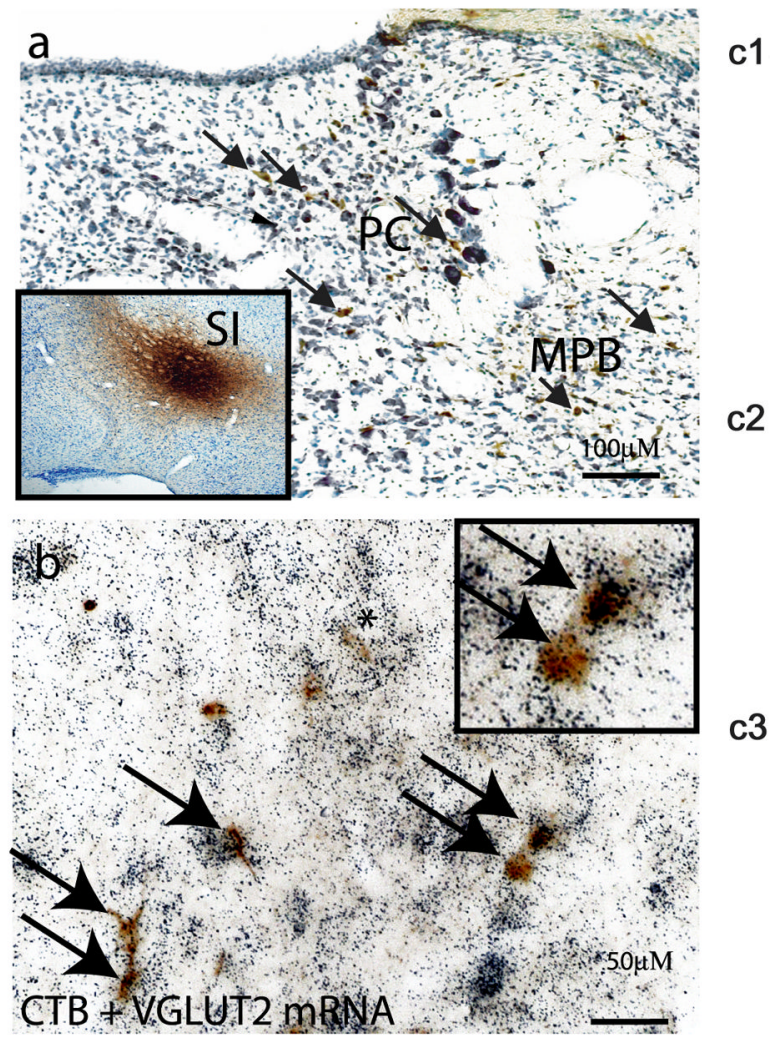

c1

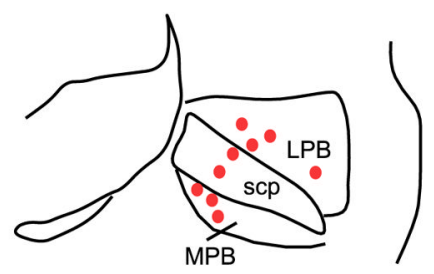

c2

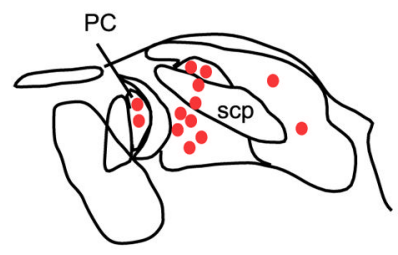

c3

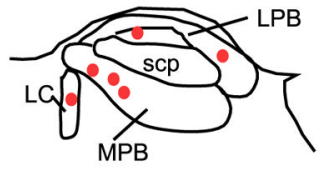

$200 \mu \mathrm{M}$

Figure 9.

Forebrain projections of the parabrachial nucleus (PB) and pre-coeruleus area (PC). (a) The retrograde tracer CTB (stained brown immunohistochemically) is shown in the substantia innominata (SI, see inset), and retrogradely labeled neurons (brown) are seen in both the PC and the adjacent medial PB (marked by arrows). (b) Double labeling with VGLUT2 mRNA radioisotopic in situ hybridization (black silver grains), after an injection of CTB into the SI (brown cells) shows that most neurons in the PB/PC that project to the BF express VGLUT2 mRNA (arrows). The inset shows an enlargement of two doubly-labeled neurons marked by arrows just below the box. (c) An illustration of the distribution of the CTB-labeled cells in the dorsolateral pontine region after an SI injection. Sections c1-c3 are arranged from rostral to caudal. Each dot $=3$ cells. 

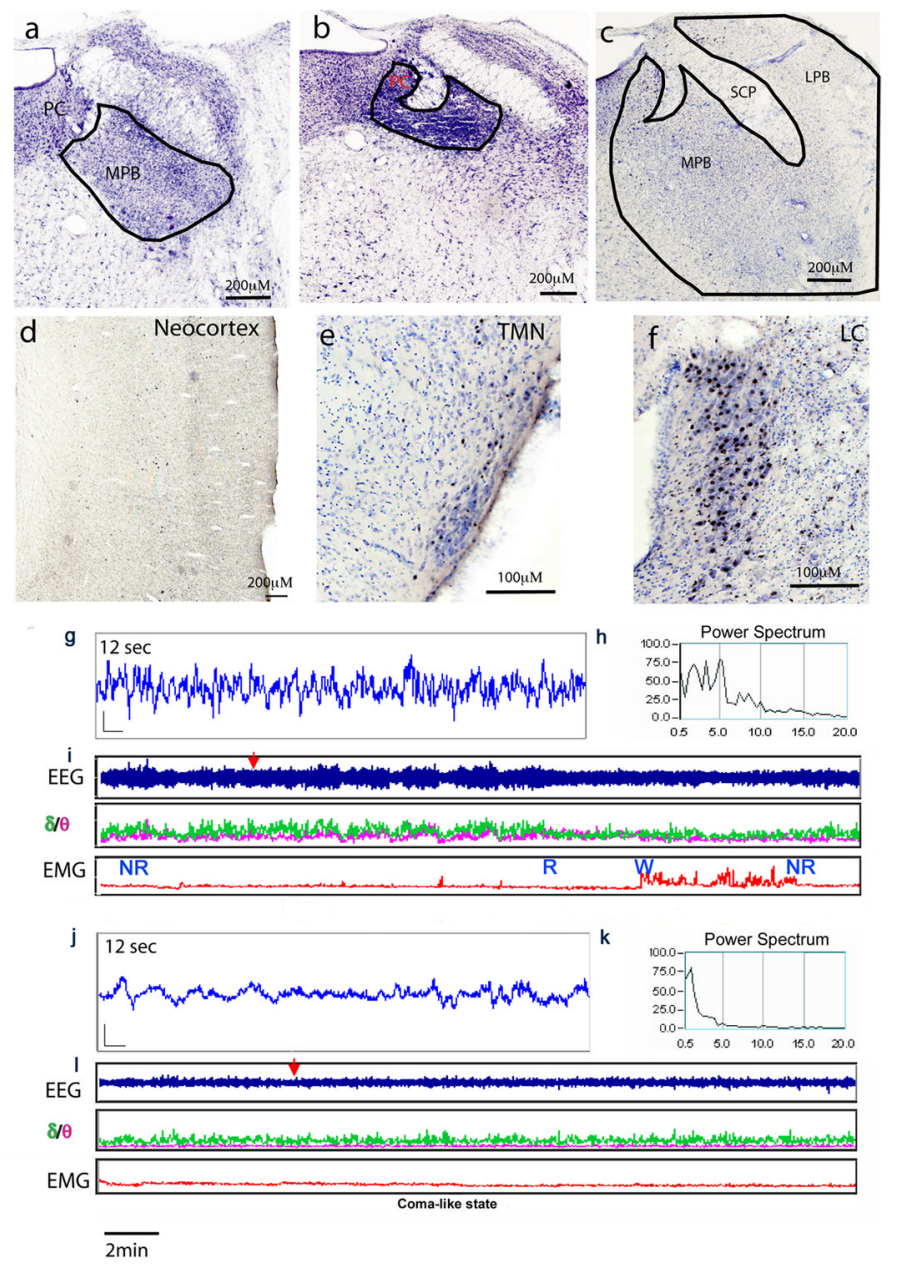

Figure 10.

Effects of cell-selective lesions of the dorsolateral pontine tegmentum on sleep and wakefulness. OX-SAP lesions of the MPB (a) caused an increase in the amount of both NREM and REM sleep during the dark period (Table 2, see also Lu et al., 2006). Lesions involving both the MPB and the PC (b) also showed loss of theta power in the EEG during REM sleep (see Lu et al., 2006). Larger lesions involving both the PC as well as the entire PB (c) caused coma with failure of continuous stimulation to activate Fos expression in the cerebral cortex (d) and reduced activation of the TMN (e; cf. fig. 8c or g), although Fos expression in the LC (f) was elevated. Panels g-l compare the physiology of a normal sleepwake cycle $(\mathrm{g}-\mathrm{i})$ with the coma-like state $(\mathrm{j}-\mathrm{l})$. $(\mathrm{g})$ shows a representative 12-sec EEG epoch and (h) associated power spectrum (epoch begins at red arrow shown in the EEG trace from (i)) from an intact rat during NREM sleep. (i) shows the EEG (top trace) and EMG (bottom trace) during a period of NREM sleep, then REM sleep and then wake. The middle trace demonstrates the relative magnitude and changes in delta ( $\delta$; green trace) and theta $(\theta$; magenta trace) power during this recording window. (j) shows a representative 12-sec EEG epoch and (k) associated power spectrum (epoch begins at see red arrow shown in the EEG trace from (1)) from the same rat following a PB-PC lesion and the development of a 'comalike' state. The EEG and power spectrum from the behaviorally unresponsive animal clearly shows the predominantly $<1.0 \mathrm{~Hz}$ sub-delta activity and loss of theta. Note in (l) that the EEG is monotonous in range, with prominent delta activity throughout the trace, and low EMG activity indicating lack of spontaneous movement. Total window time for traces in (i) 
and (1) ca. 30 min (see time bar below 1$)$. (g) Vertical scale bar in $(\mathrm{g})=80 \mu \mathrm{V}$ and in $(\mathrm{j})=$ $50 \mu \mathrm{V}$, horizontal scale $=1 \mathrm{sec}$. 


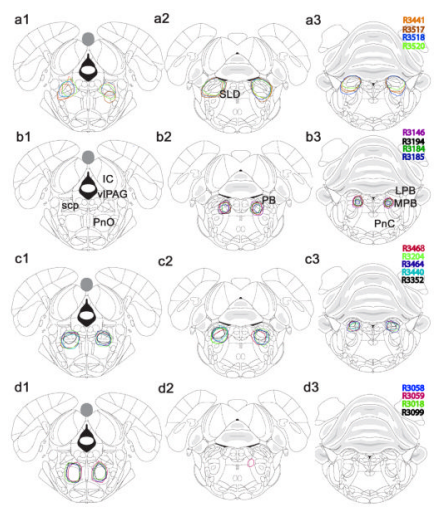

\section{Figure 11.}

Cell-body specific lesions were place in the rat pontine tegmentum by injecting orexinsaporin bilaterally. The extent of the lesions in seventeen rats are shown, including (a1-a3) four rats with complete PB/PC lesions (R3441, R3517, R3518, R3520); (b1-b3) four (of 10) rats with bilateral lesions of the SLD which also damaged the MPB (R3146, etc.); (c1-c3) five (of 7) rats with MPB lesions (R3468, etc.); and (d1-d3) four rats with bilateral lesions of the paramedian rostral pontine reticular formation (R3058, etc.). All four rats sustaining complete lesions of the $\mathrm{PB} / \mathrm{PC}$ complex became comatose. By contrast, MPB lesions and SLD lesions that included the MPB produced a significant increase in sleep (ca. 28\%) and paramedian pontine reticular formation lesions did not affect total wake or sleep time. Additional bilateral control lesions of adjacent regions of the pontine tegmentum, including the LC, the PPT, and midline raphe nuclei produced little changes in the proportion of wakefulness or sleep as previously reported (Table 4 and Lu et al., 2006). 

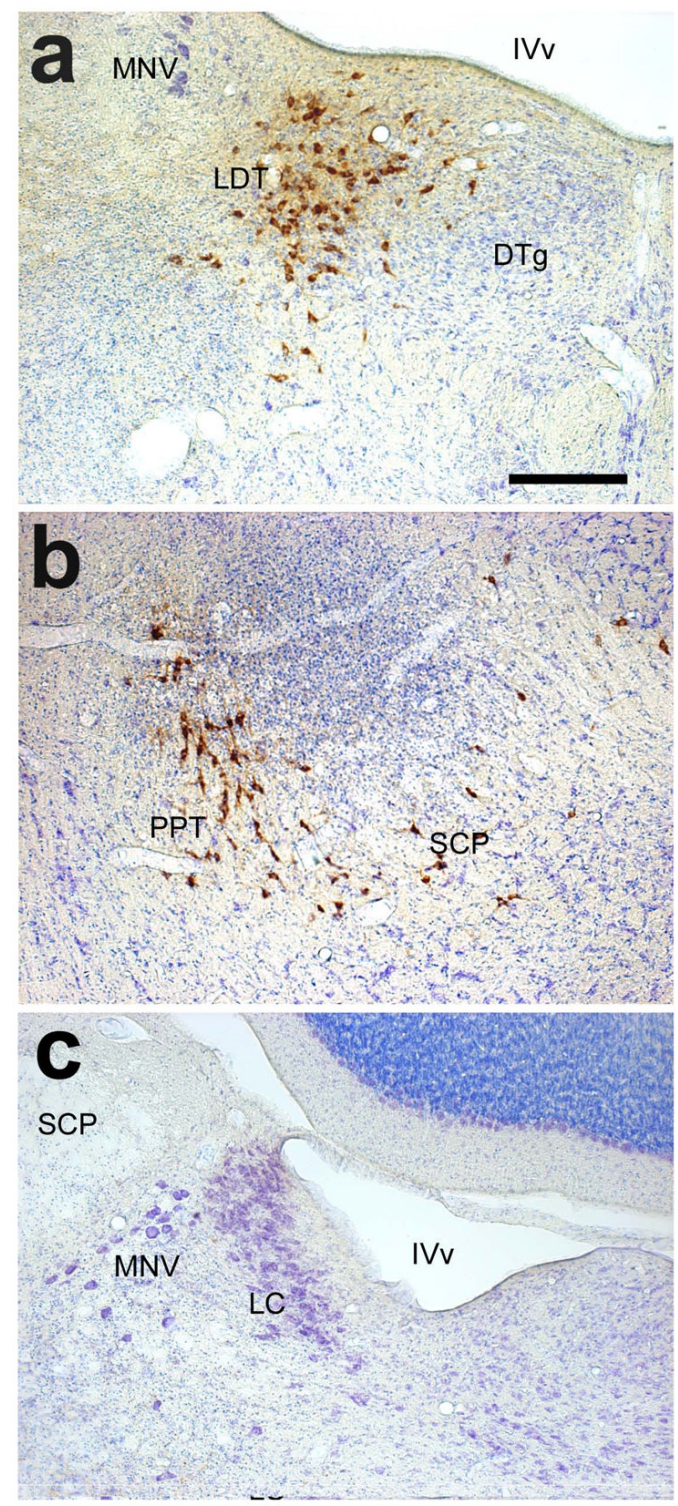

Figure 12.

Collateral effects of orexin-saporin lesions of the PB/PC on adjacent pontine regions, including the LDT, PPT and LC. The three panels show sections through the LDT (a), PPT (b), and LC (c) from a comatose rat (R3517). Panels a and b show neurons stained for ChAT immunohistochemistry (brown) and blue Nissl counterstain; panel c shows only the counterstain. While the lesions variably encroached upon all three cell groups, in no case was there more than $50 \%$ bilateral cell loss in any of these cell groups. Scale bar $=100 \mu \mathrm{m}$. 


\section{Table 1}

Table of Primary Antibodies Used

\begin{tabular}{|c|c|c|c|}
\hline Antibody & $\underline{\text { Source }}$ & $\underline{\text { Immunogen }}$ & $\underline{\text { Dilution }}$ \\
\hline c-Fos & Oncogene Sciences Ab5, rabbit polyclonal & amino acids $4-17$ of human c-Fos & 1: 50,000 \\
\hline Orexin A & Peninsula Labs T4074, rabbit polyclonal & $\begin{array}{l}\text { Pyr-Pro-Leu-Pro-Asp-Cys-Cys-Arg-Gln-Lys- } \\
\text { Thr-Cys-Ser-Cys-Arg-Leu-Tyr-Glu-Leu-Leu- } \\
\text { His-Gly-Ala-Gly-Asn-His-Ala-Ala-Gly-Ile- } \\
\text { Leu-Thr-Leu-NH } \\
\text {. }\end{array}$ & $1: 50,000$ \\
\hline Choline Acetyltransferase (ChAT) & Chemicon, AB144, goat polyclonal & human placental ChAT & $1: 2,000$ \\
\hline Tyrosine hydroxylas (TH) & Diasorin, \#22941, mouse monoclonal & rat $\mathrm{PC} 12$ cell $\mathrm{TH}$ & $1: 30,000$ \\
\hline Cholera toxin B subunit & List Biological, \#703, goat polyclonal & cholera toxin B subunit & $1: 50,000$ \\
\hline
\end{tabular}


Table 2

Effects of neurotoxic lesions of the thalamus, the basal forebrain, and the parabrachial nucleus on amounts of sleep-wake behaviors under LD 12:12

\begin{tabular}{|l|l|l|l|l|}
\hline & \%NREM/light & \%REM/light & \% NREM/dark & \%REM/dark \\
\hline Sham control $(\mathrm{n}=6)$ & $58.8 \pm 4.3$ & $8.8 \pm 0.9$ & $25.8 \pm 2.1$ & $2.7 \pm 0.9$ \\
\hline Thalamus lesion (n=6) & $64.3 \pm 3.4$ & $8.6 \pm 0.8$ & $26.1 \pm 2.3$ & $3.9 \pm 0.4$ \\
\hline Ch BF lesion ( $\mathrm{n}=4)$ & $61.8 \pm 2.9$ & $7.6 \pm 1.1$ & $27.0 \pm 3.1$ & $5.8 \pm 2.8$ \\
\hline Non-Ch BF lesion (n=4) & $57.1 \pm 2.6$ & $7.5 \pm 1.2$ & $24.8 \pm 2.6$ & $2.6 \pm 0.8$ \\
\hline LPB lesion (n=4) & $60.6 \pm 3.3$ & $5.1 \pm 3.3$ & $37.2 \pm 3.0^{*} \uparrow$ & $6.5 \pm 1.8^{*} \uparrow$ \\
\hline MPB lesion ( $=6)$ & $61.9 \pm 1.4$ & $9.6 \pm 0.8$ & $45.0 \pm 3.4^{* *} \uparrow$ & $8.4 \pm 0.2^{* *} \uparrow$ \\
\hline
\end{tabular}

* $<0.05$,

**

$\mathrm{p}<0.01$ compared to sham control lesions. 
Table 3

Fos expressing neurons (per side per section) following two-hours of behavioral arousal or gentle handling in rats with lesions of the arousal system

\begin{tabular}{|l|l|l|l|l|}
\hline & TMN & OX neurons & LC & Cingulate cortex \\
\hline Sham control & $35.8 \pm 4.0$ & $46.4 \pm 5.5$ & $51.8 \pm 4.5$ & $75.5 \pm 10.3$ \\
\hline Thalamus lesions & $34.4 \pm 4.6$ & $48.6 \pm 4.6$ & $44.4 \pm 3.0$ & $62.3 \pm 8.2$ \\
\hline BF large lesions (coma-like) & $29.2 \pm 2.9$ & $39.5 \pm 2.8$ & $43.4 \pm 2.5$ & $5.0 \pm 1.3^{* *}$ \\
\hline Ch BF lesions & $37.8 \pm 3.1$ & $46.0 \pm 3.7$ & $51.6 \pm 3.2$ & $70.4 \pm 7.8$ \\
\hline Non-Ch BF lesions & $36.0 \pm 4.8$ & $43.2 \pm 2.4$ & $53.5 \pm 4.7$ & $77.0 \pm 5.6$ \\
\hline PB/PC lesions (coma) & $6.7 \pm 1.4^{* *}$ & $8.0 \pm 2.7^{* *}$ & $57.2 \pm 5.9$ & $6.0 \pm 3.5^{* *}$ \\
\hline
\end{tabular}

${ }^{*}<0.05$,

** $\mathrm{p}<0.01$ compared to sham control lesions. 


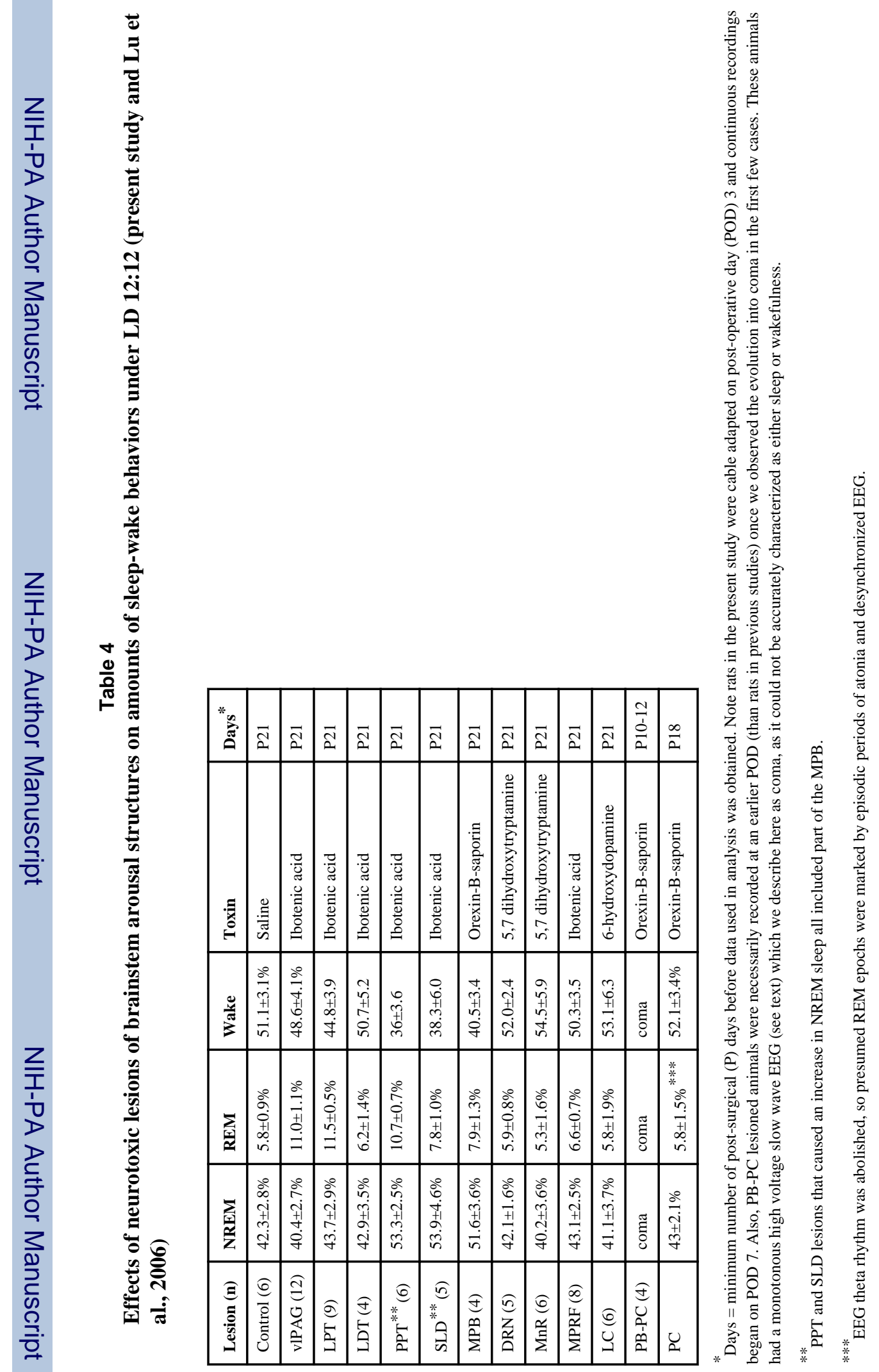

